New York University

Center for Law and Business

Working Paper \#CLB-01-005

INCENTIVES FOR VOLUNTARY DISCLOSURE

\author{
Joshua Ronen \\ New York University \\ Varda (Lewinstein) Yaari \\ Ben-Gurion University of the Negev
}

This paper can be downloaded without charge from the Social Science Research Network Electronic Paper Collection

at

http://papers.ssrn.com/paper.taf?abstract_id=155328 


\title{
INCENTIVES FOR VOLUNTARY DISCLOSURE
}

\author{
Joshua Ronen \\ New York University \\ Varda (Lewinstein) Yaari \\ Ben-Gurion University of the Negev
}

\begin{abstract}
Rule 10b-5 of the 1934 Securities and Exchange Act allows investors to sue firms for misrepresentation or omission. Since firms are principal-agent contracts between owners contract designers - and privately informed managers, owners are the ultimate firms' voluntary disclosure strategists. We analyze voluntary disclosure equilibrium in a game with two types of owners: expected liquidating dividends motivated (VMO) and expected price motivated (PMO). We find that Rule 10b-5: (i) does not deter misrepresentation and may suppress voluntary disclosure or, (ii) induces some firms to adopt a partial disclosure policy of disclosing only bad news or only good news.
\end{abstract}

Key words: Rule 10b-5, Disclosure, Noisy rational expectations equilibrium, Principal-agent contracts, Incentives.

JEL classification: G10, G30, K22, D82

Corresponding author: Joshua Ronen, Department of Accounting, Taxation, and Business Law, Stern School of

Business, New York University, 313 Tisch-Hall, New York, NY 10012-1118. E-mail jronen@ stern.nyu.edu

We are grateful to seminar participants at New York University, Tel-Aviv University, and

Baruch College, the annual meeting of the European Accounting Society in Austria 1997, the

eighth annual meeting on Financial Economics and Accounting at SUNY Buffalo, 1997, the

Study Group on Regulation and Accounting in Sienna, Italy 1998, and to Bharat Sarath, Alex

Dontoh, Jeff Callen, Jerry Feltham, Joseph Tzur, Martin Wu, Amir Ziv, Arieh Gavious, and

Rami Elitzur for their valuable comments. We are especially indebted to an anonymous referee

for numerous suggestions that improved the paper. 


\section{INTRODUCTION}

In this study, we analyze the efficiency of Rule $10 \mathrm{~b}-5$ as a mechanism that influences the incentives of firms' owners to induce managers to disclose their private information when the information is: (a) not verifiable ex-post, and (b) not subject to mandatory disclosure requirements. We also characterize the profile of prices of the firms' shares associated with the implementation of Rule 10b-5.

Under the well-known semi-strong market efficiency hypothesis, prices fully and instantaneously reflect publicly available information. This hypothesis has motivated the adoption of the "fraud-on-the-market" doctrine by the courts. Under this doctrine, investors are viewed as justified in relying on the integrity of the price as a reflection of all public information. Accordingly, the doctrine implies that investors who rely on price integrity are entitled to recovery of damages they may suffer when prices incorporate publicly disseminated misleading information (and no other information is presently publicly available to contradict it.) Securities fraud statutes and rules, such as Rule $10 \mathrm{~b}-5$, are intended to deter the dissemination of misleading information that could distort prices and, hence, damage investors. As such, Rule 10b-5 may be viewed as a mechanism for eliciting truthful disclosures.

Indeed, mechanisms that induce disclosure and thus narrow information asymmetry between management and outsiders are crucial to the success of financial markets. In addition to Rule $10 \mathrm{~b}-5$, other mechanisms that potentially can elicit truthful disclosure are:

- $\quad$ Self-induced mechanisms.

- $\quad$ Mandatory disclosure requirements. 
Self-induced mechanisms come into play when the dynamics between firms and outsiders move firms to fully disclose all available information. As Grossman (1981) has indicated, if outsiders interpret non-disclosure as the worst possible news, then firms whose information is ex-post verifiable, prefer truth-telling.

Mandating disclosure is the prerogative of both the Securities and Exchange Commission (SEC), and the body to which it delegated the task of issuing financial accounting standards in ASR 150- the Financial Accounting Standards Board (FASB). As yet, despite the many disclosure requirements imposed by reporting and disclosure rule-making bodies, firms still posses private value-rele vant information that they are not bound by law to disclose. In the second Circuit Court of Appeals decision on 11/30/93 in the matter of Time Warner Inc. Securities Litigation 9F.259.*267, the judge states:

But a corporation is not required to disclose a fact merely because a reasonable investor would very much like to know that fact. Rather, an omission is actionable under the Securities Law only when a corporation is subject to a duty to disclose the omitted fact.

[For a detailed analysis of the corporation's "affirmative duty to disclose" and the extent of its sweep, see Bauman (1979).] Typically, information with no affirmative duty to disclose consists of non- verifiable data, such as a predicted state of the environment. This implies that the market cannot induce firms to disclose their private information honestly by interpreting non-disclosure as bad news and penalizing false disclosure.

As briefly mentioned above, Rule $10 \mathrm{~b}-5$ and related rules constitute a mechanism designed to preserve the inte grity of the financial markets, because it makes unlawful any omission or misrepresentation of value-relevant information [full 
citation is provided in Section 6.] If a firm voluntarily discloses misleading information, then class action suits based on Rule 10b-5 may be filed. If a firm omits material information, the omission may become actionable.

Since firms are principal-agent contracts, firms' owners (the principals) might design contracts that induce privately informed managers (the agents) to disclose information truthfully. We analyze voluntary disclosure by modeling a firm as a oneshot principal-agent game. The manager possesses private, non- verifiable, information, which will be disclosed only if his contract induces such disclosure. The principal - the designer of the manager's contract - is either owners whose actions are motivated by their expectations of the stock price (price-motivated-owners, or PMO) or owners whose actions are motivated by the expectation of liquidating dividends (VMO). Neither the type of owners designing the manager's contract, nor the contract itself, is publicly observable.

Our analysis is divided into two parts: We first study the incentives for voluntary disclosure in an unregulated environment. As a benchmark case, we analyze the equilibrium when the information is verifiable. We find that firms disclose the truth. VMO wish to design a truth-inducing contract because of its favorable contracting value (motivating effort at a lower cost). Since the value of firms that do not disclose is lower that the value of those that do, PMO induce truthful disclosure as well. We conclude that in this case Rule $10 \mathrm{~b}-5$ is of no relevance because a self-induced mechanism elicits truthful voluntary disclosure.

When the manager's private information is non-verifiable, we find that, while VMO wish to design a truth-inducing contract, PMO are likely to prefer a policy of disclosing only good news. Since the market cannot distinguish between firms whose contract designers are VMO (VM firms) with good news and firms whose contract 
designers are PMO (PM-firms), the market believes only bad news and discounts good news. ${ }^{1}$ Thus, the expected stock price of VMO-firms is understated and the expected price of PMO-firms is overstated.

In the second half of the paper, we introduce Rule 10b-5 of the 1934 Securities and Exchange Act, which makes misrepresentation unlawful. We examine whether the penalties implied by Rule 10b-5 lead owners to design a truth-inducing contract. The analysis shows that PMO are not affected by Rule 10b-5: (1) if the price is inflated, they do not bear the cost of litigation-related damages, since they would have already exited the firm, and (2) if the price is deflated, they can claim against the firm after selling their shares. Thus, the ultimate bearers of the penalties induced by Rule 10b-5 are the VMO. Because the firm cannot unambiguously prove to the satisfaction of the courts that the disclosure was truthful, Rule 10b-5 might depress the incentives of VMO to design truth-inducing contracts.

We find that Rule $10 \mathrm{~b}-5$ is not effective. If penalties are not too high, the equilibrium remains as in the unregulated environment with non-verifiable information. That is, PMO design a good-news contract while VMO design a truthinducing contract and the consequence is that the price of PM-firms is overstated while the price of VM-firms is understated. If penalties are high, VMO prefer nondisclosure, which is mimicked by PMO. In this equilibrium, the price of each firm reflects its expected unconditional value (but not the managers' information). We also characterize the equilibrium when partial disclosure, [disclosing only one signal while withholding the other], is a feasible means for avoiding penalties associated

\footnotetext{
${ }^{1}$ For extreme parameters, the game has only a mixed-strategy equilibrium in which PMO mix between a good-news strategy and a truth-inducing contract. We will discuss this equilibrium briefly below, as it does not change results qualitatively.
} 
with the non-disclosed signal. We find that the equilibrium of the unregulated environment with non- verifiable information might obtain where non-disclosure is substituted for either good-news disclosure or bad-news disclosure. That is, VMO induce truthful disclosure of bad news (or good news) only while PMO induce nondisclosure (or good news disclosure) with the consequent distorted market price.

To sum, this paper shows that where there is information asymmetry (managers are privately endowed with information not possessed by the market), the flow of value-relevant information to the market via public disclosure is subject to distorting incentives even under existing Securities fraud statutes and case-law. The distortions are such that prices may not fully reflect all publicly disseminated information when such information is not verifiable- even when the information is true. Unsure as to whether the information is true, the market discounts it even when it is indeed true. To this extent, the "fraud on the market" doctrine may have to be revisited.

Our study is related to research analyzing disclosure as an equilibrium within a Noisy Rational Expectations framework [see e.g., Diamond, 1985, Fishman and Hagerthy, 1989, Diamond and Verrecchia, 1991, and Kim, 1993]. There are a number of features that distinguish our work from these studies. First, we treat the firm as a principalagent contract between the owners and the manager (with the two types of owners having conflicting interests). ${ }^{2}$ Second, the private information possessed by traders pertains to variables other than those about which the manager is

\footnotetext{
${ }^{2}$ Kim (1993) also analyzes a model with owners who have conflicting preferences. However, while he allows for different owners within the same firm, we assume that the owners' type determines the firm's type uniquely: firms with VMO are VM-firms and firms whose contract designers are PMO are PM-firms .
} 
privately informed. There is, therefore, no conflict between the firm's disclosure and the informed traders' incentives to acquire costly private information. (When such a conflict exists, truthful disclosures may not be socially desirable.) Third, the manager's private information is non-verifiable ex-post, so that the truth cannot be elicited simply by demanding disclosure and ascertaining (perfectly) ex-post whether the disclosure was truthful.

The paper proceeds as follows: Section 2 presents the model. Section 3 provides definitions and preliminaries. Section 4 analyzes the benchmark case where the manager possesses verifiable information. Sections 5 and 6 solve for the equilibrium with and without legal restrictions imposed by Rule 10b-5, respectively. Section 7 summarizes.

\section{THE MODEL}

The firm is modeled as a principal agent game between owners (the principal) and the manager (the agent). The firm yields a gross liquidating dividend, $x$, henceforth referred to as the outcome, which takes value from a binary set, $x \in$ $\left\{x_{1}, x_{2}\right\}, x_{1}<x_{2}$. The outcome depends stochastically on the unobservable effort, $a$, of the risk-averse, work-averse manager.

The time-line is presented in Figure 1. The events in boldface comprise the standard principal agent relationship.

$$
\text { Insert Figure } 1 \text { about here. }
$$

On Date 1, owners design the manager's contract, $C($.), based on mutually observable variables, as specified below. The contract determines the incentives of the manager to choose effort. 
On Date 2, the manager alone observes a pre-decision, imperfect signal on the state, $s$, before choosing unobservable actions, $a$. The pre-decision signal, $s$, could be either favorable, f, or unfavorable, u, i.e., $s \in\{\mathrm{u}, \mathrm{f}\}$, and it is common knowledge that the prior probability that the signal is favorable is $\gamma$, i.e., $\operatorname{Prob}[s=f]=\gamma$. The private signal received by the manager is not verifiable ex-post.

The focus of this study is the Date 3 manager's voluntary disclosure (or nondisclosure) of the signal, $m, m \in\{\mathrm{u}, \mathrm{f}\} \cup\{\varnothing\}$, where $\varnothing$ indicates non-disclosure. In particular, we ask whether the owners design a contract that induces the manager to disclose the true signal, $m=s$.

We assume that the market opens on Date 3, after the unobservable outcome is realized but before the firm publicizes the financial reports on Date 4. In addition to the owners, the market participants are:

- informed traders, who receive a noisy signal of outcome, $n, n \in\left\{n_{1}, n_{2}\right\}$,

- noise traders, who mask the demand of the informed traders; and,

- a risk-neutral market maker, who sets the market price, $\mathrm{P}$. The market maker's objective is to break even by minimizing the difference between the Date- 3 price and the expected liquidating dividends. In what follows, we denote by $\mathrm{L}$ the reduction in his utility when he fails to equate the Date-3 price to the expected liquidating dividends.

The sequence of events regarding the market subgame is:

1. After observing the firm's disclosure, some traders-informed traders, choose the accuracy of the signal, $?_{1 m}, ?_{1 m}=\operatorname{Prob}\left(\mathrm{n}_{\mathrm{t}} \mid x_{\mathrm{t}}\right), \mathrm{t}=1,2,1 / 2 \leq \rho_{1 m} \leq 1$, acquired at cost of $\mathrm{T}\left(?_{1 m}\right)$ where $\mathrm{T}$ is a convex monotone increasing function with $\mathrm{T}^{\prime}(1 / 2)=0$ and $\mathrm{T}^{\prime}(1)=\infty$. Since the expected profit is proportional to the difference between the informed traders' valuation of the firm and the expected price, $\mathrm{E}\left[x-\mathrm{P} \mid m, \mathrm{n}_{\mathrm{t}}, ?{ }_{1 m}\right]$, 
we let the informed traders' demand function, $D^{\mathrm{I}}$, as a fraction of total outstanding shares (the quantity demanded is determined in stage 3 of the market subgame) be a continuous increasing function of $\mathrm{E}\left[x-\mathrm{P} \mid m, \mathrm{n}_{\mathrm{t}}, ?{ }_{1 m}\right], D^{\mathrm{I}}: \mathrm{R} \rightarrow \mathrm{R}$.

The accuracy of the signal is chosen then to maximize the following objective function,

$\forall m, m=\mathrm{u}, \mathrm{f}, \varnothing$,

$\operatorname{Max} \sum_{\mathrm{t}} \operatorname{prob}\left(\mathrm{n}_{\mathrm{t}} \mathbf{C O N} m, \rho_{1 m}\right) D^{\mathrm{I}}\left(\mathrm{E}\left[x-\mathrm{P} \mid m, \mathrm{n}_{\mathrm{t}}, ?_{1 m}\right]-\mathrm{T}\left(?_{1 m}\right)\right.$. $?_{1 m}$

Our assumptions on $\mathrm{T}$ imply that in equilibrium, informed traders choose a signal's quality, $?_{1 m} * 1 / 2<?_{1 m} *<1 .{ }^{3}$ [It can be proved that $?_{1 m} *$ varies with $m$.]

2. Informed traders receive a signal, either $n_{1}$ or $n_{2}$.

3. Informed traders and noise traders submit their demanded quantities to the market maker. It is easy to verify that when the informed traders observe $n_{1}, E[x-$ $\left.\mathrm{P} \mid m, \mathrm{n}_{\mathrm{t}}\right]<0$ and when they observe $\mathrm{n}_{2}, \mathrm{E}\left[x-\mathrm{P} \mid m, \mathrm{n}_{\mathrm{t}}\right]>0$. In what follows, we refer to their demanded quantity when they observe $\mathrm{n}_{1}$ as low, $\ell_{m}^{\mathrm{I}}$, and when they observe $\mathrm{n}_{2}$ as high, $h_{m}^{\mathrm{I}}$. Note that the informed traders' demanded quantity is conditioned on the firm's disclosure, $m$, the signal, $\mathrm{n}$, its accuracy, $?_{1 m}{ }^{*}$, the expected market price $\mathrm{E}\left[\mathrm{P} \mid m, \mathrm{n}_{\mathrm{t}}\right]$, and their wealth after paying $\mathrm{T}\left(?_{1 m}\right)$ for the signal.

4. The market-maker observes the market demand, $w_{m}, w_{m} \in\{\ell \mathrm{u}, \ell \mathrm{f}$, $\left.\ell \varnothing, h_{u}, h_{\mathrm{f}}, h_{\varnothing}\right\}$, where $\ell_{m}$ denotes low demand and $\mathrm{h}_{m}$ denotes high demand, and sets the price, $\mathrm{P}\left(w_{m}, m\right)$. It is common knowledge that, because of noise trading,

${ }^{3}$ At $?_{1_{m}}=1 / 2$, the difference between firm valuation and expected market price is zero. Informed traders can improve upon that by increasing $?_{1_{m}}$ at no additional cost since $\mathrm{T}^{\prime}(\mathrm{t} / 2)=0$. At $?_{1 m}=1$ the quality is prohibitively costly. 
publicly observable demand reflects the demand of informed traders with probability $\rho_{2 w}$. That is, $\operatorname{Prob}\left(h_{m} \mid h_{m}^{\mathrm{I}}\right)=\rho_{2 h}$ and $\operatorname{Prob}\left(\ell_{m} \mid \ell_{m}^{\mathrm{I}}\right)=\rho_{2 \ell}, 1 / 2<\rho_{2 w}<1$. The higher $\rho_{2 w}$, the more transparent the market price with respect to informed traders' private knowledge. The gross market price (before subtracting the manager's compensation) is:

$$
\begin{aligned}
& \operatorname{Pg}^{\mathrm{g}}\left(m, w_{m}\right)=\operatorname{Prob}\left[x_{2} \mid m, w_{m}\right] x_{2}+\left[1-\operatorname{Prob}\left(x_{2} \mid m, w_{m}\right)\right] x_{1}, \\
& m \in\{\mathrm{u}, \mathrm{f}\} \cup\{\varnothing\}, w_{m} \in\left\{\left\{\ell_{m}\right\},\left\{h_{m}\right\}\right\} .{ }^{4}
\end{aligned}
$$

Both the market-maker and the informed traders are Bayesian players. It can be shown by a fairly straightforward argument that the informed traders' demand is high (low) when they observe $\mathrm{n}_{2}\left(\mathrm{n}_{1}\right)$. This implies that the information content the market-maker extracts from observed market demand is governed by the following: $\operatorname{Prob}\left[w_{m}=h_{m} \mid x_{2}\right]=?_{m h}, \operatorname{Prob}\left[w_{m}=\ell_{m} \mid x_{1}\right]=?_{m l}, \operatorname{Prob}\left[w_{m}=h_{m} \mid x_{1}\right]=1-?_{m h}$, and $\operatorname{Prob}\left[w_{m}=\ell_{m} \mid x_{2}\right]=1-?_{m l}$, where: $?_{m w}=?_{1 m} * \rho_{2 w}+\left(1-?_{1 m} *\right)\left(1-\rho_{2 w}\right), m=\mathrm{u}, \mathrm{f}, \varnothing$, $w=h, \ell$. In words: the probability of high (low) market demand conditional on the outcome being $x_{2}\left(x_{1}\right)$ for a given disclosure, $m$, equals the probability of the compound event that market demand either correctly reflects the private information of the informed traders who correctly received a signal $n_{2}\left(n_{1}\right)$, or incorrectly reflects the private information of the informed traders who incorrectly received a signal $n_{1}$ $\left(\mathrm{n}_{2}\right)$.

Figure 2 presents the equilibrium path of the market subgame.

\footnotetext{
Insert Figure 2 about here.

${ }^{4}$ When the legal penalties of Rule 10b-5 are admitted into the analysis in section 6 below, the price will be shown to deviate from (1) upon a truthful disclosure of an unfavorable signal.
} 
While the actual outcome, $x$, is realized on Date 3 and observed only by the manager on Date 4, owners do not observe it until Date 5, long after the manager is paid (upon eventual liquidation or merger). On Date 4, the firm issues a publicly observable, audited mandatory report $r, r \in\left\{x_{1}, x_{2}\right\}$, which is publicized before the manager is paid. ${ }^{5}$ The auditing technology has a one-sided error (see e.g., Schwartz, 1997). If the manager communicates the truth to the auditor, the audited report will be truthful for sure; but if the manager misrepresents the outcome to the auditor, the latter discovers the truth with probability $\mathrm{p}$. We assume that an auditor's finding that the agent misrepresented is not contractible, because information obtained during the audit is confidential. The manager attempts to misrepresent only $x_{1}$, since, by the well-known insight of the incentives literature, his compensation must be an increasing function of performance (to induce higher effort). Consequently, $\operatorname{Prob}\left[r=x_{1} \mid x_{1}\right]=\mathrm{p}, \operatorname{Prob}\left[r=x_{1} \mid x_{2}\right]=0, \operatorname{Prob}\left[r=x_{2} \mid x_{1}\right]=1-\mathrm{p}$, and $\operatorname{Prob}\left[r=x_{2} \mid x_{2}\right]=1$. The combined effect of the unobservability of outcome and the imperfection of the auditing technology is to endow additional information, such as disclosure of the manager's signal, with positive contracting value. ${ }^{6}$

\footnotetext{
${ }^{5}$ Note that the owners cannot use the much-delayed knowledge of $x$ on Date 5 to force truthful reporting of the outcome on Date 4.

${ }^{6}$ Bhattacharya and Krishnan (1999) make the interesting point that the market can deter earnings management: informed traders acquire perfect information at some cost upon receiving a goodoutcome report, and the market-maker makes use of the observable order-flow following a good report in setting the price. In such a setting a "sell" flow following a good-outcome report leads to a very low price, which disciplines the manager who wishes to misrepresent a bad outcome. This equilibrium obtains only if the informed traders' information acquisition costs are not too high. In our paper, perfect information is prohibitively costly to informed traders; in any case, we focus on the market that opens before the financial reports are issued so as to investigate the incentives for disclosing soft, non-
} 
The contract of the manager is designed by a subset of the firms' owners and their representatives. The wealth of the owners is determined by their time of exit: owners who sell their shares on Date 3 collect the market price, $\mathrm{P}(. .$,$) , while owners$ who stay until Date 5, collect liquidating dividends net of payment to the manager, $x$ - $C(m, \mathrm{P}, r)$. As Hart (1995) and others have noted, there are two types of owners: owners that are motivated by the price $-\mathrm{PMO}$, and owners motivated by the expected value - VMO. [Henceforth, firms whose contract designers are PMO (VMO) are designated PM-firms (respectively VM-firms).] That is, on Date 3, the wealth of owners of type $\mathrm{O}, \mathrm{W}_{3}^{\mathrm{O}}\left(m, w_{m}\right)$, who design contract $C^{\mathrm{O}}, \mathrm{O}=\mathrm{VMO}, \mathrm{PMO}$, is:

$$
\mathrm{W}_{3}^{\mathrm{O}}\left(m, w_{m}\right)=\mathrm{a}^{\mathrm{O}} \mathrm{P}\left(m, w_{m}\right)+\left(1-\mathrm{a}^{\mathrm{O}}\right) \mathrm{E}\left(x-C^{\mathrm{O}} \mathrm{I}^{\mathrm{O}}\right]
$$

where $\mathrm{P}$ is the information set of type $\mathrm{O}$ owners on Date 3 , and $\mathrm{a}^{\mathrm{O}}$ is an indicator function, $\mathrm{a}^{\mathrm{O}}=1$ if owners type $\mathrm{O}$ sell on Date $3, \mathrm{a}^{\mathrm{O}}=0$ if they collect liquidating dividend on Date 5. In what follows, we assume that PMO prefer to sell their shares on Date 3. That is, unless the expected Date-5 liquidating dividend is strictly higher than the Date-3 price, PMO exit on Date 3. In contrast, VMO stay until Date 5, regardless of the Date- 3 price, i.e. $\mathrm{a}^{\mathrm{VMO}}=0$. The intuition is that PMO experience strictly negative, infitisimal utility from staying, while VMO suffer infinite negative utility from selling at Date 3 .

It is common knowledge that in $\mathrm{d}$ fraction of the firms the contract designers are $\mathrm{VMO}, 0<\mathrm{d}<1$. But neither the manager's contract nor the type of owners designing it is observed by the market (noise traders mask the trades/non-trades of the contract designers). ${ }^{7}$ Hence, if both types induce the same disclosure, the marketmaker cannot distinguish between a VM firm and a PM firm.

outcome information.

${ }^{7}$ Firms are not required to publicize all details of managers' contracts in the proxies they file with the 
The risk-averse, work-averse manager maximizes his expected von Neumann-Morgenstern utility function over compensation, net of disutility over effort, $\mathrm{E}[\mathrm{W}(C(m, \mathrm{P}, r))]-\mathrm{V}(a)$, where $\mathrm{W}^{\prime}>0, \mathrm{~W}^{\prime}<0, \mathrm{~V}^{\prime}>0, \mathrm{~V}^{\prime \prime}>0$. He is willing to accept the contract only if it guarantees him his reservation utility, Wo.

The manager's effort belongs to a binary set, $a \in\left\{a_{\mathrm{p}}, a_{\mathrm{g}}\right\}, a_{\mathrm{g}}>a_{\mathrm{p}}\left(a_{\mathrm{g}}\right.$ is the good--performance effort and $a_{\mathrm{p}}$ is the poor-performance level of effort). We assume that the owners prefer the good-performance level of effort, $a_{\mathrm{g}}$, for each signal.

Consequently, the manager's compensation will vary with performance measures such as reported earnings and market price. We denote the probability that the outcome is $x_{2}$ conditional on the signal, $s$, and effort, $a$, by $\theta_{a}^{s}$ i.e., $\operatorname{Prob}\left[x=x_{2} \mid s, a\right]=\theta_{a}^{s}$.

(Superscripts denote the signal and the subscripts refer to effort.) In what follows, we assume that $\theta_{\mathrm{g}}^{S}>\theta_{\mathrm{p}}^{S}$, ${ }^{8}$ i.e., the higher the effort level, the higher the probability of $x_{2}$. We also assume that the productivity of effort is higher when the signal is favorable; i.e., $\theta_{\mathrm{g}}^{S}-\theta_{\mathrm{p}}^{\mathrm{f}}>\theta_{g}^{\mathrm{u}}-\theta_{\mathrm{p}}^{\mathrm{u}}$.

Table 1 summarizes the main notation.

Insert Table 1 about here.

Securities and Exchange Commission (SEC), because it is considered proprietary information whose disclosure might trigger harmful consequences to the firm. The people that design and know the manager's contract in detail form a small group.

${ }^{8}$ To simplify notation, we write $\theta_{a_{\mathrm{g}}}^{s}=\theta_{\mathrm{g}}^{s}$, and $\theta_{a_{\mathrm{p}}}^{s}=\theta_{\mathrm{p}}^{s}$. 


\section{DEFINITIONS AND PRELIMINARIES}

To ease presentation, we introduce some terminology in the following definitions.

Definition 1: Define a truth-telling profile (TTP) as the vector $(C(.) \mathrm{P}()$.$) ,$ such that:

1. Each owner's type designs a truth-inducing contract: $C^{O}(m=s, \mathrm{P}, r)$, $\mathrm{O}=\mathrm{PMO}, \mathrm{VMO}$.

2. The market-maker fully incorporates each firm's disclosure in the price, i.e.,

$$
\mathrm{P}^{\mathrm{g}}\left(m, w_{m}\right)=\operatorname{Prob}\left[x_{2} \mid \mathrm{s}, . .\right]\left[x_{2}-x_{1}\right]+x_{1}
$$

The definition of TTP captures the thrust of our paper. Truthful voluntary disclosure takes place when the owners design a truth-inducing contract. But it does not suffice that firms disclose the truth; we also require that the market-maker believes the truth such that the information is incorporated in the price; i.e., that the market be semi-strong efficient with respect to truthful disclosures.

Definition 2: A Truth-telling-Bayesian Nash Equilibrium (TTBN) is an equilibrium in which TTP is the only equilibrium profile of contracts and marketmaker's beliefs.

Note that TTP resolves the other components of the Bayesian-Nash equilibrium (see Definition 26.1 in Osborne and Rubinstein, 1994) along the equilibrium path. In response to owners designing a truth-inducing contract, each 
manager discloses his private signal truthfully, $m=s$, and exerts the good-

performance effort, $a_{\mathrm{g}}$. VMO exit on Date 5. Since the market-maker believes the disclosure, he sets a price that fully incorporates all available information, i.e., the Date 3 price equals the expected Date 5 liquidating dividend. In response, PMO sell their shares at Date 3. [The informed traders' strategy was specified in Section 2. In particular, note that when the firm discloses the truth, $\left.\operatorname{Prob}\left[x_{2} \mid m\right]=\theta_{\mathrm{g}}^{S}.\right]$

We require the truth-inducing profile to be in pure strategies, because, with mixed strategies, the players randomize between their strategy in TTP and other strategies. Consequently, under mixed strategies, with some positive probability the ex-post strategies' profile might have owners not designing a truth-inducing contract, or the market-maker not believing disclosure, or both.

We solve for a contract that minimizes the expected cost of compensating the manager as follows:

(P1) $\left.\min _{C} \mathrm{E} C().\right]$

s.t.

$\mathrm{E}[\mathrm{W}(C())]-.\mathrm{V}\left(a_{\mathrm{g}}\right)=\mathrm{Wo}$.

$$
\begin{aligned}
\forall s, \quad\left(a_{\mathrm{g}} m=s\right) \in \underset{ }{a \in\left\{a_{\mathrm{p}}, a_{\mathrm{g}}\right\}} & \operatorname{argmax} \mathrm{E}[\mathrm{W}(C(.) \mid s)]-\mathrm{V}\left(a_{\mathrm{g}}\right) . \\
& m \in\{\mathrm{u}, \mathrm{f}\} \cup\{\varnothing\}
\end{aligned}
$$

The contract minimizes the expected compensation cost, subject to guaranteeing the manager his reservation utility, Wo, (the (PC) constraint), inducing good-performance level of effort, $a_{\mathrm{g}}$ and truthful disclosure for each signal (the (IC) constraints). There are three types of incentive constraints. For each signal, $s$, the manager is induced to exert the good-performance effort, given that he discloses the 
truth, (IC. $a_{s}$ ); to disclose the true signal given that he exerts the good-performance level of effort, (IC. $\left.m_{s}\right)$; and to disclose the true signal and exert the good-performance level of effort instead of misrepresenting and exerting the poor-performance level of effort, (IC. $\left.a m_{s}\right), s, m=$ u,f. ${ }^{9}$

Lemma 1: Regardless of whether the manager's private signal is verifiable or not,

(a) The contract's cost when the manager is induced to make a truthful disclosure is lowest.

(b) The expected value of a firm, $\mathrm{E}[x-C]$, that conditions the manager's compensation on the truthful disclosure of his private signal is higher than that of a firm that does not.

\section{Proof: See Appendix.}

The proof of part (a) is based on showing that (as the first-order conditions indicate) the optimal contractual payments differ across messages, $m$, for a given report, $r$, and market price, $\mathrm{P}(. .$.$) . Since a solution in which the payment to the$ manager is independent of $m$ is feasible, this characterization implies that a truth revealing voluntary disclosure reduces the cost of the manager's contract. ${ }^{10}$ Part (b) is

\footnotetext{
${ }^{9}$ We do not include constraints involving non-disclosure. Since non-disclosure is clearly observable, it can be deterred by an appropriate penalty.

${ }^{10}$ In the Appendix, we provide numerical examples. For the same set of parameters, when the information is non-verifiable, a disclosure contract's cost is 117.3 and a non-disclosure contract's cost is 117.637> 117.3. When the information is verifiable, the cost of a truth-inducing contract is $111.49<117.637$
} 
a corollary to Part (a). Since the expected outcome is the same but the contract's cost is lower, the value of the firm for the owners is higher when the manager is induced to make truthful voluntary disclosure. The intuition of this lemma is that when the contract does not induce disclosure, the manager's payment is the same whether the signal is favorable or unfavorable. But when the manager is induced to disclose the truth, the owners can reduce the contract's cost, since when $s=f$, the productivity of effort is higher, owners can offer the risk-averse manager an improved risk-sharing arrangement.

Note that this result holds irrespective of whether the manager's private signal is verifiable. When the information is non-verifiable, the truth-inducing contract is more costly than when the information is verifiable. When the signal is verifiable, the contract designer can elicit the truth by designing a penalty contract; the penalty imposed upon verifying that the agent did not disclose the truth must exceed the agent's expected gains from misrepresentation. This results in a less costly contract than when the information is not verifiable (technically, in the Appendix we show that (IC.m) are binding only when the signal is non-verifiable). Now, since the optimal solution entails truth elicitation when disclosure is non-verifiable, it is plainly evident that when the information is verifiable, the (less costly) contract is optimally based on the verifiable signal as well.

Definition 3: A contract that induces disclosing the signal that is associated with the highest (lowest) firm's value, even when it is not true, is a good-news (badnews) contract. 
In what follows, without loss of generality, we assume that the favorable signal is associated with good news. I.e., a contract inducing $m=\mathrm{f}$ is a good news contract.

Note that under a good-news contract, just as under a contract that elicits no disclosure, voluntary disclosure does not reveal the manager's private signal.

\section{THE EQUILIBRIUM WHEN THE INFORMATION IS VERIFIABLE}

As a benchmark result, we analyze the incentives for truthful voluntary disclosure when the manager's information is verifiable and where legal institutions and penalties, specified under the securities law, do not affect the considerations to disclose. By definition, verifiable information implies that a third party can verify whether the firm disclosed the truth. Hence, disclosure becomes contractible in such a way as to make possible the elimination of misrepresentation. For example, when the false news might inflate (deflate) price, each share can be coupled with a 'put' ('call') option that allows the buyer (seller) to sell (buy) back the share when the truth is publicly revealed. It is clear then that verifiable information cannot be misrepresented. The implication of this discussion is that the disclosure decision reduces to choosing between truth- revealing disclosure and non-disclosure.

\section{Proposition 1:}

When the information of the manager is verifiable, TTBN exists.

Proof: See Appendix

Proposition 1 is reminiscent of a well-known result in "persuasion games,"

originated in the seminal paper by Grossman (1981). See also Milgrom and Roberts 
(1986), Shin (1994), and Bhattacharya and Krishnan (1999). The verifiability of the disclosure implies one of two outcomes: truthful disclosure or no disclosure. Since, by Lemma 1, VMO induce truth telling, the market maker will treat non-disclosure as bad news and thus induce PMO to have the manager always disclose the truth.

\section{THE EQUILIBRIUM WHEN THE INFORMATION IS NON-VERIFIABLE}

In this section, we analyze the equilibrium and examine the plausibility that the equilibrium is TTBN when the manager's information is non-verifiable. That is, truthful disclosure by the firm cannot be perfectly verified by a third party

\subsection{The equilibrium}

\section{Proposition 2:}

Let $\mathrm{d}=\bar{\delta}=\frac{\left.\mathrm{E}\left[C\left(w_{\varnothing}, r\right)\right)-\mathrm{E}\left(C\left(m, w_{m}, r\right)\right)\right]}{\left.?\left(\mathrm{~A}\left(w_{\mathrm{f}}\right)-\mathrm{B}\left(w_{\mathrm{f}}\right)\right)+(1-?)\left(\mathrm{E}\left[C\left(w_{\varnothing}, r\right)\right)-\mathrm{E}\left(C\left(m, w_{m}, r\right)\right)\right]\right)}$.

Where $C(w \varnothing, r)$ is a non-disclosure contract. ${ }^{11}$ Then, TTBN does not exist. In equilibrium,

(a) VMO design a truth-inducing contract, and PMO design a goodnews contract.

(b) The disclosure/market-price profile is:

- When the firm discloses unfavorable news, $m=\mathrm{u}$, the market price fully reflects the unfavorable news, i.e., $\mathrm{P}\left(\mathrm{u}, w_{\mathrm{u}}\right)=\mathrm{E}\left[x-C\left(m, w_{m}, r\right) \mid s=\mathrm{u}, w_{\mathrm{u}}\right]$.

- When the firm discloses favorable news, $m=$ f, the market price, $\mathrm{P}$, discounts the disclosure of a VM firm with good news, and is given by:

\footnotetext{
${ }^{11}$ Because of the correspondence between market demand and price, there is no loss of generality in denoting compensation by $C\left(, . w_{m} .,\right)$.
} 


$$
\mathrm{P}\left(\mathrm{f}, w_{\mathrm{f}}\right)=\frac{? \mathrm{~d}}{? \mathrm{~d}+(1-\mathrm{d})} \mathrm{A}\left(w_{\mathrm{f}}\right)+\frac{1-\mathrm{d}}{? \mathrm{~d}+(1-\mathrm{d})} \mathrm{B}\left(w_{\mathrm{f}}\right),
$$

where: $\mathrm{A}\left(w_{\mathrm{f}}\right)=\mathrm{E}\left[x-C\left(\mathrm{f}, w_{\mathrm{f}}, r\right) \mid s=\mathrm{f}, w_{\mathrm{f}}\right]$, and $\mathrm{B}\left(w_{\mathrm{f}}\right)=\mathrm{E}\left[x-C\left(w_{\mathrm{f}}, r\right) \mid w_{\mathrm{f}}\right]<\mathrm{A}\left(w_{\mathrm{f}}\right)$.

- When the firm does not disclose, the price lies between the goodnews price and the value of a firm with bad news, i.e., $\min \left\{\mathrm{E}\left[x-C\left(w_{\varnothing}, r\right) \mid s=\mathrm{u}\right], \mathrm{P}\left(\mathrm{u}, w_{\mathrm{u}}\right)\right\}=\mathrm{P}\left(\varnothing, w_{\varnothing}\right)=\mathrm{P}\left(\mathrm{f}, w_{\mathrm{f}}\right)$.

Proof: See Appendix .

Proposition 2 establishes that, unlike the case when information is verifiable, a truth-telling equilibrium (where all firms disclose the truth and the market-maker believes them) does not exist. VMO will design a truth-inducing contract, because, by Lemma 1, their residual share of the firm's value is higher. That is, designing a truth-inducing contract is a dominant strategy for the VMO.

A higher market price for good-news disclosure when the market maker believes the disclosure rules out the possibility of PMO designing a truth-inducing contract. PMO will refrain from designing a non-disclosure contract as well since non-disclosure would reveal their firm to be PM. If $\mathrm{d}$ is sufficiently high, the knowledge that the market-maker will attribute some positive probability to a goodnews disclosure being truthful (after all, VMO design a truth-inducing contract) leads PMO to pool with VMO by designing a good-news disclosure contract. When good news is disclosed, the market-maker knows that with conditional probability $\gamma d(\gamma d+(1-d))$ it is truthful because the contract designers are VMO (and thus the value of firm equals $\left.\mathrm{A}\left(w_{\mathrm{f}}\right)\right)$, and that with probability $(1-\mathrm{d}) /(\gamma \mathrm{d}+(1-\mathrm{d}))$ the contract designers are PMO and the disclosure is uninformative, so that the value of the firm equals $\mathrm{B}\left(w_{\mathrm{f}}\right)<\mathrm{A}\left(w_{\mathrm{f}}\right)$ (the last inequality is proved in the Appendix). 
Finally, since non- disclosure is an off-equilibrium move, Bayes' rule cannot be used to calculate the market-maker's beliefs. Clearly, the price cannot be lower than the lowest possible value of a firm with bad news. To sustain the equilibrium, the non-disclosure price cannot exceed the good-news price, because if it did, the best response of PMO then will be to induce non disclosure. The manager's compliance with owners' wishes is secured by appropriate design of his incentives.

Proposition 2 shows that the equilibrium depends on the proportion of VM firms, $\mathrm{d}$. If $\mathrm{d}<\delta$, the equilibrium involves mixed strategies: the PMO randomize between designing good-news disclosure contracts and truth-inducing contracts while the market maker randomizes between trusting the report and discounting its content. Table 2 illustrates the absence of equilibrium in pure strategies.

Insert Table 2 about here.

The intuition is evident from equation 2: upon a good-news disclosure, the market price approximates the value of a firm whose owners design a non-disclosure contract, $\mathrm{E}\left[x-C\left(\mathrm{w}_{\varnothing}, r\right)\right]=\mathrm{E}[x-C(w, r)]$, which is lower than the value of a firm whose owners design a truth-inducing contract, $\mathrm{E}\left[x-C\left(m, w_{m} r\right)\right]$. PMO will therefore prefer to design a truth-inducing contract and not sell their shares when $m=$ f. At the critical d (denoted by $\bar{\delta}$ ), the expected payoff for PMO when selling at a discounted price, $\mathrm{E}_{w}\left[\mathrm{P}\left(\mathrm{f}, w_{\mathrm{f}}\right)\right]$, equals the payoff from designing a truth-inducing contract and keeping their shares when $m=\mathrm{f}, \mathrm{E}_{s, \mathrm{w}, \mathrm{r}}\left[x-\mathrm{C}\left(m, w_{m}, r\right)\right]$. If, on the other hand, the market-maker trusts the disclosure because he believes that PMO design a truth-inducing contract, PMO are better-off designing a good-news disclosure contract

In this mixed-strategy equilibrium, TTP exists with some positive probability: all owners design truth-inducing contracts and the market-maker believes the 
disclosures. TTBN does not exist because TTP is not the only equilibrium profile.

Since our analysis of the mixed-strategy equilibrium does not affect our results qualitatively, we shall proceed assuming that $\mathrm{d}$ is sufficiently high.

Note that, regardless of $\mathrm{d}$, the requirement that the disclosure policy be an equilibrium rules out a scenario where, to avail themselves of the contracting value, VMO buy out from the PMO the right to design the contract: Suppose, by contradiction, that PMO did sell out to the VMO. Then, the PMO can extract from $\mathrm{VMO}$, at most, the expected value of a VM firm, $\mathrm{E}\left[x-C\left(m, r, w_{m}\right)\right]$. The rational market maker believes now that he faces only VM firms. Hence, he accepts any disclosure as truthful and sets the price, $\mathrm{P}\left(m, w_{m}\right)=\mathrm{E}\left[x-C\left(m, r, w_{m}\right) \mid m=s, w_{m}\right]$. In particular, the price for good news, $m=f$ exceeds the expected value of a firm making truthful disclosure of bad and good news,

$$
\mathrm{P}\left(\mathrm{f}, w_{\mathrm{f}}\right)=\mathrm{A}\left(w_{f}\right)>\mathrm{E}\left[x-C\left(m, r, w_{m}\right) \mid w_{m}\right] .
$$

[The first equality follows from the market maker believing the good-news disclosure. The last inequality follows from the definition of good news, since $\mathrm{A}\left(w_{\mathrm{f}}\right)$ is the value of a firm with good news, while the expected value of a VM firm averages over good, $\mathrm{A}\left(\mathrm{w}_{\mathrm{f}}\right)$, and bad news.] Therefore, if the market maker believes that VMO buy out the design right from the PMO, the best response of PMO is not to sell and design a good-news disclosure contract.

\section{Theorem 1:}

The expected market price, $\mathrm{E}[\mathrm{P}()$.$] , understates (overstates) the expected$ liquidating dividends, $\mathrm{E}[x-\mathrm{C}() \mid. ., . .)$.$] , of VM (PM)- firms.$

The proof of Theorem 1 is immediate from Proposition 2. Theorem 1 
establishes the existence of a market failure in an unregulated environment. PM firms' incentives to misrepresent cause the expected market price of VM (PM) firms to be understated (overstated). While the price reflects the firm's value conditional on disclosure of bad news, it understates the firm's value conditional upon a truthfully disclosed favorable signal, so that the expected price understates the unconditional value of the VM firm. For the PM firm, the price is a weighted average of the firm's true value and the higher value of a firm that induced truthful disclosure and where the signal is favorable. The expected price, then, overstates the unconditional fundamental value (the expected net liquidating dividends) ${ }^{12}$.

\section{RULE 10B-5}

Rule 10b-5 of the 1934 Securities Exchange Act states:

\footnotetext{
${ }^{12}$ Note that our results carry over to a multi-period setting, where firms and managers could allegedly build reputation. The point is that reputation will not alter the incentives of owners or the manager in any given period. The manager will always find it in his best interest to act in a manner that is consistent with his compensation contract, i.e., act in accordance with the equilibrium derived in this single -period model Similarly, VMO and PMO will always comply with their equilibrium strategy: there is no reputation to be built. Also, in a multi-period setting, the market will not be able to infer the identity of VM firms over time, because the identity of the contract designer (VMO or PMO) changes randomly over time. [That is, observing bad-news disclosure in the past does not imply that VMO designed the manager's contract at present]
} 
It shall be unlawful for any person, directly or indirectly...

(a) [t]o employ any device, scheme, or artifice to defraud,

(b) [t]o make any untrue statement of a material fact or to omit to state a

material fact necessary in order to make the statements made, in light of the circumstances under which they were made, not misleading, or

(c) [t]o engage in any act, practice, or course of business which operates or would operate as a fraud or a deceit upon any person, in connection with the purchase or sale of any security. 17 C.F.R $240.10 b-5$.

In this section, we admit into the analysis Rule $10 \mathrm{~b}-5$ of the 1934 Securities Exchange Act. The firm operates within a legal environment in which shareholders can file class-action suits against corporations for misrepresentations or omissions that allegedly caused injury to the plaintiffs. ${ }^{13}$

Since the ultimate owners of these corporations are shareholders, a classaction suit redistributes wealth among shareholders. Specifically, the damages recovered by plaintiffs under Rule 10b-5 and the costs of litigation are borne by the non-plaintiff class of shareholders (see, e.g., Arlen and Carney, 1992). ${ }^{14}$ Consequently, we analyze the effect of Rule 10b-5 litigation on owners. In particular, we expect the ultimate bearers of Rule $10 \mathrm{~b}-5$ 's penalties to be the VMO because the PMO are likely to quit the firm by the time a class-action suit is filed, and in some cases, they are the plaintiffs.

\footnotetext{
${ }^{13}$ As will become clear below, not all omissions give rise to liability and damages.

14 Although managers are named as the defendants (in addition to the corporation) in the lawsuits, they rarely, if ever, end up personally incurring the costs of litigation. These are borne by the corporation shareholders (as residual owners ) both directly, in the form of settlements, and indirectly, in the form of premia paid for liability insurance for directors and officers.
} 


\subsection{The effect of Rule lOb-5 on the model}

The possible incidence of Rule 10b-5 recoveries under different prices and disclosures are summarized in Table 3.

\section{Insert Table 3 about here.}

\subsubsection{Misrepresentation}

\section{Under the prevailing "fraud on the market" doctrine, ${ }^{15}$ Rule $10 b-5$ can be}

${ }^{15}$ The "Fraud on the market" doctrine stipulates that plaintiffs need not prove reliance on the firm's misrepresentation because capital markets are semi-strong efficient. That is, reliance is presumed (albeit rebuttable by the defendants) because the plaintiffs are justified in assuming the integrity of the market price, i.e., that the price reflects all disseminated information (including misrepresentation). Before the courts adopted the "fraud on the market" doctrine, plaintiffs had to prove individual reliance on financial statements or other documents containing alleged misrepresentation or omissions.

The "information on the market" doctrine was articulated by the Court of Appeals, Re: Apple Computer Securities Litigation, No .88-1617, D.C. Cv-84-20148(A)-RPA, 1989. The judge stated:

...In a fraud on the market case, the plaintiff claims that he was induced to trade stock not by any particular representations made by corporate insiders, but by the artificial stock price set by the market in light of statements made by the insiders as well as other material public information. Provided that they have credibly entered the market through other means, the facts allegedly omitted by the defendant would already be reflected in the stock's price; the mechanism through which the market discovered the facts in question in not crucial.... However, it is a basic assumption of the securities laws that the partially-informed investors will cancel each other out, and that Apple's stock price will accurately reflect all relevant information. (11911-11912) 
invoked in two scenarios: (1) Shareholders file a class-action suit on Date 4, demanding recovery of losses they sustained when the audited report is $\mathrm{r}=x_{1}$, because the price they paid at Date 3 upon purchase, $\mathrm{P}\left(\mathrm{f}, h_{\mathrm{f}}\right)$, was purposely inflated. Allegedly, managers were aware that there existed a high likelihood that the outcome to be reported on Date 4, would be $r=x_{1}$. (2) Shareholders who sold their shares on Date 3 file a class-action suit on Date 4, demanding recovery for opportunity losses they sustained because the price they received on Date $3, \mathrm{P}(\mathrm{u}, \ell \mathrm{u})$, was below the true value, given that the firm reports $r=x_{2}$.

The actionable allegations in such suits are the misrepresenting disclosures of the firm. In the first case, the price was inflated because the firm disclosed good news, $m=\mathrm{f}$, and the associated penalty is $\mathrm{D}^{\mathrm{f}} \approx \psi^{\mathrm{f}}\left(\mathrm{P}\left(\mathrm{f}, h_{\mathrm{f}}\right)-\mathrm{P}^{\prime}\left(\mathrm{u}, h_{\mathrm{u}}\right)\right)$, where $\psi^{\mathrm{f}}$ is a function of stock ownership, the volume of shares traded, and other factors, and $\mathrm{P}^{\prime}\left(\mathrm{u}, h_{\mathrm{u}}\right)$ is the estimated price conditional upon bad news, $\mathrm{P}^{\prime}\left(\mathrm{u}, h_{\mathrm{u}}\right)<\mathrm{P}\left(\mathrm{f}, h_{\mathrm{f}}\right)$. In the second case, the price was deflated because the firm disclosed bad news, with the associated penalty of $\left.\mathrm{D}^{\mathrm{u}} \approx \psi^{\mathrm{u}}\left(\mathrm{P}^{\prime}\left(\mathrm{f}, \ell_{\mathrm{f}}\right)-\mathrm{P}\left(\mathrm{u}, \ell_{\mathrm{u}}\right)\right), \mathrm{P}^{\prime}\left(\mathrm{f}, \ell_{\mathrm{f}}\right)>\mathrm{P}\left(\mathrm{u}, \ell_{\mathrm{u}}\right)\right)$, where $\mathrm{P}^{\prime}\left(\mathrm{f}, \ell_{\mathrm{f}}\right)$ is the estimated price conditional upon good news.

If the firm discloses good (bad) news and then reports a good (bad) outcome, buyers (sellers) will suffer no material loss and no materially harmful misrepresentation can be established (cases superscripted with (1) in Table 3). Also, because of the "information on the market" doctrine, class-actions suits are not successful when $m$ and $w_{m}$ have opposite signs, $\left\langle m, w_{m}\right\rangle \in\left\{\left\langle\mathrm{f}, \ell_{\mathrm{f}}\right\rangle,\left\langle\mathrm{u}, h_{\mathrm{u}}\right\rangle\right\}$. If, for example, the firm discloses good news, a low market demand would probably indicate that offsetting bad news is available to the market, i.e., there existed "information on 
the market" (cases superscripted with (2) in Table (3)). ${ }^{16}$

\title{
6.1.2. $\underline{\text { Omission }}$
}

A plaintiff may base a Rule 10b-5 claim on an omission only when the defendant failed to disclose a material fact under a duty to do so. Such a duty arises when the disclosure is required by a statute or regulation, or is necessary to make a statement non-misleading (see, e.g., Basic Inc. v. Levinson, 485 U5224,239 end.17 (1988): "silence, absent a duty to disclose is not misleading under rule 10b-5". In the absence of prior voluntary disclosures, management is not obliged to disclose private information that "updates" or "corrects" the implication of prior non- disclosed, private information. A voluntary disclosure of some information item, A, triggers the affirmative duty to later disclose information item B if B corrects A such that B's non-disclosure could materially mislead the market. ${ }^{17}$

Formally, in our model, the firm decides on voluntary disclosure only once. But affirmative duty to disclose can be determined only in light of prior disclosure (before Date 3 in our time-line) if any. That is, if the firm had adopted a strict nondisclosure strategy, and hence chose not to voluntarily disclose at any point before Date 3, no duty to disclose is triggered on Date 3. Omission is not actionable in this

\footnotetext{
${ }^{16}$ For a detailed discussion of these issues refer, for example, to Simmonds, Sagat, and Ronen (199293), and the numerous references therein.

${ }^{17}$ In the matter of Weiner v. The Quacker Oats Company, 129F.3d 310(1997), the judge ruled in favor of the appellants, stating:
}

\begin{abstract}
Although securities fraud statute and regulation do not impose duty on defendants to correct prior statements, particularly statement of intent, so long as those statements were true when made, duty to correct prior statements does exist if prior statements were true when made but misleading if left unrevised; to avoid liability in such circumstances, notice of change of intent must be disseminated in timely fashion.
\end{abstract}


case. Therefore, a strategy of disclosing neither the favorable signal, $s=$ f, nor the unfavorable signal, $s=\mathrm{u}$, should eliminate the duty to disclose and hence will not give rise to damages. In this case, plaintiffs do not recover (cases superscripted with (3) in Table 3).

What if the firm adopts a partial disclosure strategy - truthful disclosure of only favorable signals or only unfavorable signals? This strategy is different because any non-disclosure now is informative. For example, if only favorable signals are disclosed, the rational market-maker will interpret non-disclosure as bad news, triggering a drop in the price to $\mathrm{P}\left(\mathrm{u}, \mathrm{w}_{\mathrm{u}}\right)$. Suppose a good outcome is reported. ${ }^{18}$ Since non-disclosure is interpreted as a bad-news signal, can it be claimed that the firm misled the market by not disclosing? In other words, can damage be assessed and recovered under a partial disclosure strategy?

The situation is murky because of the ambiguity of the outcome of litigation: the non-verifiability of the manager's possession of a favorable signal implies that damage could be assessed and a penalty imposed on the firm. On the other hand, the burden of proof that the defendants concealed material information with intent to mislead falls on the plaintiffs. Hence, plaintiffs may expect no recovery in this case, as they would need to provide evidence that management likely learned a favorable signal when in fact management received an unfavorable signal; this could be difficult to establish.

In what follows, we present the main results assuming that under a partial disclosure strategy plaintiffs recover, just as under full disclosure. We also analyze the game under the assumption of non-recovery and proceed to show that our conclusions

${ }^{18}$ A subsequent report of a bad outcome will not cause a recoverable loss; hence, there will be no damages (similar to cases superscripted with (1) in Table 4). 
are not altered. That is, in general, there exists no truth-telling equilibrium (TTBN).

\subsection{The owners' incentives}

\subsubsection{The effect of Rule 10b-5 on the price and the incentives of PMO.}

The damages imposed under a Rule 10b-5 regime can cause the market price to deviate from the prices derived in section 5. With the disclosure of good news, there is some probability that the reported outcome will be $r=x_{1}$ and that market demand will be $h_{\mathrm{f}}$ The equilibrium price will be as determined in section 5, and the buyers will be able to recover damages $\mathrm{D}^{\mathrm{f}}$. To illustrate, suppose the true expected value is $\$ 32$, and $E\left[D^{f}\right]=\$ 2$. Buyers will be willing to pay $\$ 32$ because upon litigation and settlement they will hold shares valued at $\$ 30$ each and cash in the expected amount of $\$ 2$ a share. ${ }^{19}$

With the disclosure of bad news, however, there is some probability that the reported outcome will be $r=x_{2}$ and that market demand will be $\ell_{\mathrm{u}}$. Sellers will be able to recover damages, $\mathrm{D}^{\mathrm{u}}$. Buyers will pay no more than the expected value less the damages the firm will have to pay the sellers. Sellers will be willing to receive no more than this reduced price because they will anticipate collecting $E\left[D^{\mathrm{u}}\right]$. To illustrate, suppose the expected liquidating value is $\$ 25$ and $E\left[D^{\mathrm{u}}\right]$ is $\$ 2$. Buyers will not be willing to pay more that $\$ 23$ (\$25 less expected damages of $\$ 2$ ), and sellers will be willing to accept $\$ 23$ since they expect to collect $\$ 2$ in damages.

The following observation summarizes this analysis.

\footnotetext{
${ }^{19}$ Note that the recovery of damages occurs even without misrepresentation because of the assumption of non-verifiability. That is, even without misrepresentation, the uncertainty of a trial's outcome typically will induce plaintiffs and defendants to settle at some cost to the corporation named in the suit. This expected cost is denoted by $\mathrm{E}[\mathrm{D}]$ or $E\left[\mathrm{D}^{\mathrm{u}}\right]$.
} 
Observation 1: Compared to an unregulated regime, Rule 10b-5 causes the market price to decrease by the amount of expected damages, $E\left[D^{\mathrm{u}}\right]$, upon bad-news disclosure but leaves it unaffected upon good-news disclosure.

Lemma 2: Suppose VMO design a truth-inducing contract. Then, under Rule 10b-5, the strategy of PMO is the same as in a regime without Rule 10b-5: PMO design good-news disclosure contracts.

The proof is immediate from Observation 1. Given non-verifiability, if VMO design a truth-inducing contract, Rule 10b-5 does not alter the incentives of PMO to induce good-news disclosure: The price plus expected damages equals the price characterized in section 5, and its expectation is maximized by good-news disclosure. That is, if VMO prefer truth-telling, the market equilibria with and without Rule 10b-5 are the same.

\subsubsection{The incentives of $V M O$}

For now, we consider four possible pure disclosure strategies: $:^{20}$

- $\quad$ Truth-telling.

- $\quad$ Non-disclosure.

Partial misrepresentation:

\footnotetext{
Always disclosing a favorable signal (which is true when the signal is

${ }^{20}$ If partial disclosure triggers penalties, there is no loss of generality in restricting the analysis to these alternatives. The case in which partial disclosure does not trigger penalties is analyzed separately below.
} 
- Always disclosing an unfavorable signal (which is true when the signal is indeed unfavorable).

There is theoretically another alternative: Always misrepresenting - disclosing a favorable signal when it is unfavorable, and disclosing an unfavorable signal when it is favorable. This alternative reveals the true signal. If it is an equilibrium disclosure strategy under Rule 10b-5, the first alternative — truth telling — can be induced, because all participants: the courts, the market maker, and investors will invert the message and extract the truth.

Partial misrepresentation and non-disclosure are equivalent in terms of the manager's contract's cost. Therefore, the difference between them depends on the incidence of litigation. The following can be shown.

\section{Observation 2:}

A contract that induces partial misrepresentation is inferior to a non-disclosure contract for VMO.

\section{Proof: See Appendix.}

While both a non-disclosure contract, and a contract that induces partial misrepresentation deprive the owners of the contracting value of truth-revealing disclosure, a non-disclosure contract does not expose the VMO to Rule 10b-5 penalties, since the law does not entitle plaintiffs to damages upon non-disclosure of information "without affirmative duty to disclose"

Observation 2 narrows the search for the equilibrium strategy to comparing truth telling with non-disclosure. The possibility of litigation creates a dilemma for 
VMO since if they stay with the firm they are the shareholder-group that bears the costs of a class-action suit. The potential conflict of interest between shareholders who retain their shares and those who sell during a class period is well recognized. ${ }^{21}$

\subsection{The effect of Rule 10b-5 on the existence of TTBN}

This section summarizes the results in section 6.2.

\section{Theorem 2:}

The introduction of Rule 10b-5 fails to yield TTBN. In particular, there are two mutually exclusive equilibria:

(a) If the expected damages are lower than the saving in the compensation cost yielded by designing a truth-inducing contract, i.e., $\mathrm{E}_{s, w}\left[\mathrm{D}^{\mathrm{s}}\right]<$ $\mathrm{E}_{s, u}\left[\mathrm{C}\left(m, w_{\mathrm{m}}, r \mid m=s\right)-\mathrm{C}\left(w_{m} r\right)\right], \mathrm{VMO}$ design a truth-inducing contract, and the equilibrium is as characterized by Proposition 2 .

(b) If the expected damages are higher than the saving in the compensation cost yielded by designing a truth-inducing contract, i.e., $\mathrm{E}_{s, w}\left[\mathrm{D}^{\mathrm{s}}\right]>$ $\mathrm{E}_{s, u}\left[\mathrm{C}\left(m, w_{\mathrm{m}}, r \mid m=s\right)-\mathrm{C}\left(w_{m o} r\right)\right]$, all firms design non- disclosure contracts, and the expected price equals the unconditional expected value for all

${ }^{21}$ The former are potentially adverse to those who sell their shares as explained by the court $\underline{\text { In re }}$ Zeigler Coal Sec. Litig., No 94CV 0843-PER (S.D. III Mar.29, 1996), slip op. at 13.

\footnotetext{
"[e]quity" plaintiffs such as Greenfield and Barish [who still own their stock] presumably desire to moderate damages because they are interested in limiting the total liability of the corporation to protect their holdings. Ballan v. Upiohn, 159 F.R.D. 473, 483 (W .D. Mich 1994). Class members who have already sold their Zeigler shares would be indifferent to a large damage award in the interest of maximizing their recovery against defendants. In re Seagate Techno logy II Sec. Litig., 843 F. Supp 1341,1362 (N.D. Ca. 1994).
} 
firms, $\mathrm{E}_{w}[\mathrm{~B}(w \varnothing)]$.

\section{Proof: See Appendix.}

As in the previous section, the pivot player is VMO. If they find that evading expected litigation cost by inducing non-disclosure dominates an equilibrium wherein the manager discloses the truth, then, neither VMO nor PMO, who want to pool with them, induce disclosure. In this case, the price equals the expected value of the nondisclosing firm. Because the threat of penalties does not deter PMO from designing a good-news disclosure contract, the Rule 10b-5 regime yields the same equilibrium as a regime without this rule.

The intuition of Theorem 2 is that Rule 10b-5 elicits opportunistic behavior from PMO. Since the manager's signal is non-verifiable, the owners bear penalties even when the firm discloses the truth. Theorem 2 shows that the equilibrium that can be achie ved with Rule 10b-5 is one in which the firms either do not disclose, or in which only bad news is believed (as in the equilibrium with no Rule 10b-5). Rule 10b5 therefore fails to cause the price to reflect all the information possessed by a firm's management. Moreover, it depresses the incentives to voluntarily induce disclosure. When there is no disclosure, the price reflects the unconditional (upon the signal observed by the manager) expectation of the net liquidating dividends, albeit it does not reflect the observed signals. When there is disclosure: the price understates (reflects) the VM-firm's value upon a truthful disclosure of a favorable (unfavorable) signal; the price overstates the expected PM firm's value, because a PM firm discloses only good news and the market-maker attaches positive weight to the event that the truly good news was disclosed by a VM firm. In expectation, with disclosure under Rule 10b-5, the price biases the value of VM (PM) firms downward (upward). 
We draw the attention of the reader to the fact that were VMO to sell their shares when the price exceeds expected Date -5 value, VMO always would sell upon bad news, and the penalties upon good news would be the determining factor as to whether VMO induce truthful disclosure or not.

\section{Theorem 3:}

Let non-disclosure fail to lead to recovery by plaintiffs under a partial disclosure strategy. Then, TTBN does not exist, since Rule 10b-5 suppresses disclosures.

(a) If the minimum expected litigation cost upon disclosure of only one signal, either $\mathrm{E}\left[\mathrm{D}^{\mathrm{f}}\right]$ or $\mathrm{E}\left[\mathrm{D}^{\mathrm{u}}\right]$, is lower than the savings in compensation costs attained by inducing the manager to reveal the truth, then,

- $\quad$ VMO design a partial disclosure contract. Specifically, the manager discloses the signal associated with the minimum expected litigation costs, but not the signal associated with the maximum expected litigation cost. That is, if $E\left[D^{f}\right]>\left(\right.$ respectively $<$ ) $E\left[D^{u}\right]$, VMO induce disclosure of the bad (respectively good)-news only.

- $\quad$ PMO pool with VMO: PMO design a non- disclosure contract when the VMO suppress good-news disclosure and a good-news disclosure contract when VMO suppress bad-news disclosure.

- When VMO suppress good-news disclosure: the market maker interprets non-disclosure as good news as per equation 2 , and believes bad-news disclosure When VMO suppress bad-news disclosure, the market-maker interprets good-news disclosure as good news as per equation 2, and treats non-disclosure as bad news. 
(b) If the minimum expected litigation cost upon disclosure of only one signal, i.e., $\min \left\{E\left[D^{f}\right], E\left[D^{\mathrm{u}}\right]\right\}$, exceeds the benefit from designing a truth-revealing contract, no firm will make a disclosure.

Proof: See Appendix.

The difference between Theorem 2 and Theorem 3 is that the cost of possible litigation is smaller when partial disclosure spares these costs for one of the signals. Hence, we now consider six alternative disclosure strategies for VMO instead of four by adding two partial disclosure alternatives: the firm discloses honestly only bad news or the firm discloses honestly only good news. Clearly, a partial-disclosure strategy dominates a full-disclosure strategy when non-disclosure of only one signal does not lead to penalties for omission. Which signal to disclose publicly? The answer for the VMO depends on the signal associated with the lowest litigation cost. If the minimum expected litigation cost outweighs the benefit of designing a truthrevealing contract (see Lemma 1), VMO design a non-disclosure contract and PMO pool with them. Otherwise, VMO will adopt a partial disclosure strategy of either good news if $E\left[D^{f}\right]<E\left[D^{u}\right]$ or bad news if $E\left[D^{f}\right]>E\left[D^{u}\right]$. When VMO induce partial disclosure, the payoffs are the same as in Proposition 2, since PMO pool with the good-news 'signal' of VMO. In comparison with Proposition 2, non-disclosure switches place with either good-news or bad news disclosure. The long and the short of this discussion is that Rule $10 b-5$ either does not affect the equilibrium or suppresses disclosure. When Rule 10b-5 does not suppress disclosure completely, the market price overstates the expected PM firms' value and understates the expected VM firms' value.

Note that, in contrast to Skinner (1994) and others, who contend that some 
firms make voluntary disclosures as a preventive measure to avoid class-actions suits, we find that firms prefer non-disclosure to achieve this goal. Francis et al. (1994) provide empirical evidence that is consistent with our conclusions. Sixty-two percent of firms with lawsuits in their sample made voluntary disclosure, while $87 \%$ of the firms without lawsuits did not.

\section{SUMMARY AND CONCLUSIONS}

This study addresses the incentives for truthful voluntary disclosure by firms when it is common knowledge that: (i) the designers of the manager's contract that determines his incentives to disclose can be either value-motivated owners (VMO) who do not plan to sell in the near future, or price-motivated owners (PMO), who do not sell their shares when the price understates firm's value, (ii) neither the type of owners that design the contract, nor the contract itself, is publicly observed, and (iii) managers possess non-verifiable private information, which could be disclosed voluntarily.

We study three scenarios: As a benchmark cases we assume the absence of the legal institutions and penalties specified under the securities law. In the first benchmark case, the manager's information is verifiable. We find that owners design a truth-inducing contract because of its favorable contracting value.

We then proceed to analyze the case where the information is non- verifiable. Focusing on the set of potentially value-relevant information that corporations have no affirmative duty to disclose, we ask whether owners will voluntarily design contracts that induce managers to disclose such value-relevant information publicly, so that it can be reflected in the stock price. The answer to this question is negative, since firms whose owners wish to maximize the expected price will try to pool with 
firms whose owners design truth-inducing contracts to maximize their net expected liquidating dividends.

Having established the absence of a truth-telling equilibrium (where truth is revealed and properly incorporated in the price), we ask whether a market mechanism that is based on the existing Rule $10 \mathrm{~b}-5$ and the case law interpreting it generate a truth-telling equilibrium. We find that because the information is non- verifiable, opportunistic behavior by traders might either suppress disclosure or induce misrepresentation by firms whose contract designers maximize the expected price. Thus, our answer is again negative.

In the unregulated environment, the equilibrium is such that all firms (VM and PM) will voluntarily disclose what purports to be the observed signal. However, while VM firms disclose truthfully, PM firms misrepresent by always disclosing a goodnews signal. As a result, the price will correctly reflect the private information only when VM firms disclose bad news. In expectation, the price will always bias the unconditional value of VM (PM) firms downward (upward). Hence, we do not have a truth-telling equilibrium.

In the regulated environment of Rule 10b-5, we also do not have a truth-telling equilibrium. Under some circumstances, we observe an equilibrium similar to the one in the unregulated environment, with the expected price understating (overstating) the value of VM (PM) firms. There, equilibrium prices will differ from those of the unregulated environment because they now reflect expected Rule 10b-5 penalties. Under other circumstances, either no firm will voluntarily disclose, and prices, while reflecting unbiasedly the unconditional fundamental value of all firms, will fail to reflect the privately observed information; or some firms adopt a partial disclosure policy of disclosing only bad news or only good news, with a corresponding bias in 
the price for the signal associated with good news of VM firms. 


\section{References:}

Arlen, J.H. and W.J. Carney, 1992, Vicarious liability for fraud on securities markets: theory and evidence, University of Illinois Law Review, 691-740.

Basic Inc. v. Levinson, 1988, 485 U5224, 239 end.17 1988.

Bauman, J.D., 1979, Rule 10b-5 and the corporation's affirmative duty to disclose, The Georgetown Law Journal, 67, 935-990.

Bhattacharya, U. and M. Krishnan, 1999, To believe or not to believe, Journal of Financial Markets 2, 69-98.

Cho, I-K. and D. Kreps, 1987, Signaling games and stable equilibria, Quarterly Journal of Economics 102, 179-221.

Cyert, R., S.H. Kang, P. Kumar, and A. Shah, 1997, Corporate governance, ownership structure, and CEO compensation. Working paper, Carnegie Mellon University.

Diamond D.W., 1985, Optimal release of information by firms, Journal of Finance 40(4), 1071-1094.

Dunbar, F.C. T.S. Foster, V.M. Juneja, and D.N. Martin, 1995, Recent trends: what explains settlements in shareholder class action, National Economics Research Association (N\E\R\A), June.

Fishman, M.J. and K.M. Hagerthy, 1989, Disclosure Decisions by firms and the competition for price efficiency, Journal of Finance 44, 633-646.

Francis, J., D. Philbrick, and K. Schipper, 1994, Earnings surprises and litigation risk, working paper, University of Chicago and Portland State University.

Grossman, S.S., 1981, The information role of warranties and private disclosure about product quality, Journal of Law and Economics 24, 461-483.

Hart, 0., 1995, Corporate governance: some theory and implications,. The Economic 
Journal, 105, 678-689.

Kim, O., 1993, Disagreement among Shareholders over a firm's disclosure policies, Journal of Finance. 48(2), 747-760.

Krishnan, M., 1992, On the equivalence between Kyle (1985) and Glosten-Milgrom (1985), Economics Letters 40, 333-338.

Kyle, A.S., 1985, Continuous auctions and insider trading, Econometrica 53, 13151335.

Milgrom, P.R. and J. Roberts, 1986, Relying on information of interested parties, The Rand Journal of Economics 17, 18-32.

Osborne, M.J. and A. Rubinstein, 1994, A Course in Game Theory (The MIT Press: Cambridge, Massachusetts, London, England).

Schwartz, R., 1997, Legal regimes, audit quality and investment, The Accounting Review 72, 385-406.

Skinner, D.J., 1994, Why firms voluntarily disclose bad news, Journal of Accounting Research 32(1), 38-60.

Simmonds, R., K.A. Sagat K.A. and J. Ronen, 1992-93, Dealing with anomalies, confusion and contradiction in fraud on the market securities class actions, Kentucky Law Journal 81, 123-186.

Shin, H.S., 1994, News management and value of firms, The Rand Journal of Economics 25, 171-185. 


\section{APPPENDIX}

\section{Proof of Lemma 1:}

Part (a):

The proof is based on solving the following program:

$\min \mathrm{E}[C()$.

C

s.t.

$\mathrm{E}[\mathrm{W}(C())]-.\mathrm{V}\left(a_{\mathrm{g}}\right)=\mathrm{Wo}$.

(PC)

$\begin{aligned} \forall s, \quad\left(a_{\mathrm{g}} m=s\right) \in & \underset{a \in\left\{a_{\mathrm{p}}, a_{\mathrm{g}}\right\}}{\operatorname{argmax} \mathrm{E}\left[\mathrm{W}(C(. \mid s)]-\mathrm{V}\left(a_{\mathrm{g}}\right) .\right.} \\ & m \in\{\mathrm{u}, \mathrm{f}\} \cup\{\varnothing\}\end{aligned}$

Specifically, the participation constraint is:

$\mathrm{E}[\mathrm{W}(C())]-.\mathrm{V}\left(a_{\mathrm{g}}\right)=\gamma \mathrm{EW}(., ., . m=\mathrm{f})+(1-\gamma) \mathrm{EW}(., ., ., m=\mathrm{f})$,

where:

$\mathrm{EW}\left(., ., . m=\mathrm{f}, a_{\mathrm{g}}\right)=\left[?_{\mathrm{fh}} \theta_{g}^{\mathrm{f}}+(1-\mathrm{p})\left(1-?_{\mathrm{fh}}\right)\left(1-\theta_{g}^{\mathrm{f}}\right)\right] \mathrm{W}\left(C\left(\mathrm{f}, h_{\mathrm{f}}, x_{2}\right)\right)+$

$\left[\left(1-?_{\mathrm{fl}}\right) \theta_{g}^{\mathrm{f}}+(1-\mathrm{p}) ?_{\mathrm{fl}}\left(1-\theta_{g}^{\mathrm{f}}\right)\right] \mathrm{W}\left(C\left(\mathrm{f}, \ell_{\mathrm{f}}, x_{2}\right)\right)+\mathrm{p}\left(1-\theta_{g}^{\mathrm{f}}\right) \mathrm{W}\left(C\left(\mathrm{f}, x_{1}\right)\right)$.

$\operatorname{EW}\left(., ., . m=\mathrm{u}, a_{\mathrm{g}}\right)=$

$\left[?_{\mathrm{u} h} \theta_{g}^{\mathrm{u}}+(1-\mathrm{p})\left(1-?_{\mathrm{u} h}\right)\left(1-\theta_{g}^{\mathrm{u}}\right)\right] \mathrm{W}\left(C\left(\mathrm{u}, h_{\mathrm{u}}, x_{2}\right)\right)+$

$\left[\left(1-?_{\mathrm{ul}}\right) \theta_{g}^{\mathrm{u}}+(1-\mathrm{p}) ?_{\mathrm{ul}}\left(1-\theta_{g}^{\mathrm{u}}\right)\right] \mathrm{W}\left(C\left(\mathrm{u}, \ell_{\mathrm{u}}, x_{2}\right)\right)+\mathrm{p}\left(1-\theta_{g}^{\mathrm{u}}\right) \mathrm{W}\left(C\left(\mathrm{u}, x_{1}\right)\right)$ 
Note that we took advantage of the fact that in equilibrium the contract is independent of the price when the report is $x_{1}$. This is a special case of the informativeness criterion of Holmstrom (1979). A report of a low outcome fully reveals the actual outcome, $\mathrm{r}^{-1}\left(r=x_{1}\right)=x_{1}$, eliminating the need for additional information that is a garbling of the actual outcome.

The incentive constraints include three types. For each signal, $s$, the manager is induced to exert the good-performance effort, given that he discloses the truth,
$\forall s, \quad \mathrm{EW}\left(m, \mathrm{P}, r \mid m=s, a_{\mathrm{g}}\right)=\mathrm{EW}\left(m, \mathrm{P}, r \mid m=s, a_{\mathrm{p}}\right)$.
$\left(\mathrm{IC} \cdot a_{s}\right)$

Specifically,

When $s=\mathrm{f}$,

$\left[?_{\mathrm{fh}} \theta_{g}^{\mathrm{f}}+(1-\mathrm{p})\left(1-?_{\mathrm{fh}}\right)\left(1-\theta_{g}^{\mathrm{f}}\right)\right] \mathrm{W}\left(C\left(\mathrm{f}, h_{\mathrm{f}}, x_{2}\right)\right)+$

$\left[\left(1-?_{\mathrm{fl}}\right) \theta_{g}^{\mathrm{f}}+(1-\mathrm{p}) ?_{\mathrm{fl}}\left(1-\theta_{g}^{\mathrm{f}}\right)\right] \mathrm{W}\left(C\left(\mathrm{f}, \ell_{\mathrm{f}} x_{2}\right)\right)+$

$\mathrm{p}\left(1-\theta_{g}^{\mathrm{f}}\right) \mathrm{W}\left(C\left(\mathrm{f}, x_{1}\right)\right)=$

$\left[?_{\mathrm{fh}} \theta_{g}^{\mathrm{f}}+(1-\mathrm{p})\left(1-?_{\mathrm{fh}}\right)\left(1-\theta_{g}^{\mathrm{f}}\right)\right] \mathrm{W}\left(C\left(\mathrm{f}, h_{\mathrm{f}} x_{2}\right)\right)+$

$\left[\left(1-?_{\mathrm{fl}}\right) \theta_{g}^{\mathrm{f}}+(1-\mathrm{p}) ?_{\mathrm{fl}}\left(1-\theta_{g}^{\mathrm{f}}\right)\right] \mathrm{W}\left(C\left(\mathrm{f}, \ell \mathrm{f}, x_{2}\right)\right)+$

$\mathrm{p}\left(1-\theta_{g}^{\mathrm{f}}\right) \mathrm{W}\left(C\left(\mathrm{f}, x_{1}\right)\right)$

(IC. $\left.a_{\mathrm{f}}\right)$

Rearranging, yields:

$Q_{\mathrm{fh}} \mathrm{W}\left(C\left(\mathrm{f}, h_{\mathrm{f}}, x_{2}\right)\right)+\left(\mathrm{p}-Q_{\mathrm{fl}}\right) \mathrm{W}\left(C\left(\mathrm{f}, \ell_{\mathrm{f}}, x_{2}\right)\right)-\mathrm{p} \mathrm{W}\left(C\left(\mathrm{f}, x_{1}\right)\right)=\frac{\mathrm{V}\left(a_{g}\right)-\mathrm{V}\left(a_{\mathrm{p}}\right)}{\theta_{\mathrm{g}}^{\mathrm{f}}-\theta_{\mathrm{p}}^{\mathrm{f}}}$,

where:

$$
Q_{\mathrm{fh}}=?_{\mathrm{fh}}-(1-\mathrm{p})\left(1-?_{\mathrm{fh}}\right) ; \mathrm{p}-Q_{\mathrm{fl}}=1-?_{\mathrm{fl}}-(1-\mathrm{p}) ?_{\mathrm{fl}} .
$$

Repeating the exercise for ( $\left.\mathrm{IC} a_{\mathrm{u}}\right)$ yields, 


$$
Q_{\mathrm{u} h} \mathrm{~W}\left(C\left(\mathrm{u}, h_{\mathrm{f}}, x_{2}\right)\right)+\left(\mathrm{p}-Q_{\mathrm{ul}}\right) \mathrm{W}\left(C\left(\mathrm{u}, \ell_{\mathrm{f}}, x_{2}\right)\right)-\mathrm{p} \mathrm{W}\left(C\left(\mathrm{u}, x_{1}\right)\right)=v=\frac{\mathrm{V}\left(a_{g}\right)-\mathrm{V}\left(a_{\mathrm{p}}\right)}{?_{\mathrm{g}}^{\mathrm{u}}-?_{\mathrm{p}}^{\mathrm{u}}}
$$

where: $Q_{\mathrm{u} h}=?_{\mathrm{u} h}-(1-\mathrm{p})(1-? \mathrm{u} h) ; \mathrm{p}-Q_{\mathrm{ul}}=1-?_{\mathrm{ul}}-(1-\pi) ?_{\mathrm{ul}}$.

The other incentive constraint states that the manager is induced to disclose the true signal given that he exerts the good-performance level of effort,

$\forall s, \quad \mathrm{EW}\left(m, \mathrm{P}, r \mid m=s, a_{\mathrm{g}}\right)=\mathrm{EW}\left(m, \mathrm{P}, r \mid m \neq s, a_{\mathrm{g}}\right)$.

Specifically, (IC. $m_{\mathrm{s}}$ ) is, for each signal,

When $s=$,

$$
\begin{gathered}
{\left[?_{\mathrm{fh}} \theta_{g}^{\mathrm{f}}+(1-\mathrm{p})\left(1-?_{\mathrm{fh}}\right)\left(1-\theta_{g}^{\mathrm{f}}\right)\right] \mathrm{W}\left(C\left(\mathrm{f}, h_{\mathrm{f}}, x_{2}\right)\right)+} \\
{\left[\left(1-?_{\mathrm{fl}}\right) \theta_{g}^{\mathrm{f}}+(1-\mathrm{p}) ?_{\mathrm{fl}}\left(1-\theta_{g}^{\mathrm{f}}\right)\right] \mathrm{W}\left(C\left(\mathrm{f}, \ell_{\mathrm{f}}, x_{2}\right)\right)+} \\
\mathrm{p}\left(1-\theta_{g}^{\mathrm{f}}\right) \mathrm{W}\left(C\left(\mathrm{f}, x_{1}\right)\right)= \\
{\left[?_{\mathrm{u} h} \theta_{g}^{\mathrm{f}}+(1-\mathrm{p})\left(1-?_{\mathrm{u} h}\right)\left(1-\theta_{g}^{\mathrm{f}}\right)\right] \mathrm{W}\left(C\left(\mathrm{u}, h_{\mathrm{u}}, x_{2}\right)\right)+} \\
{\left[\left(1-?_{\mathrm{ul}}\right) \theta_{g}^{\mathrm{f}}+(1-\mathrm{p}) ?_{\mathrm{ul}}\left(1-\theta_{g}^{\mathrm{f}}\right)\right] \mathrm{W}\left(C\left(\mathrm{u}, \ell_{\mathrm{u}}, x_{2}\right)\right)+} \\
\mathrm{p}\left(1-\theta_{g}^{\mathrm{f}}\right) \mathrm{W}\left(C\left(\mathrm{u}, x_{1}\right)\right) .
\end{gathered}
$$

Rearranging,

$$
A+\theta_{g}^{\mathrm{f}} B=0
$$

where: $A=(1-\mathrm{p})\left[\left(1-?_{\mathrm{f}}\right) \mathrm{W}\left(C\left(\mathrm{f}, h_{\mathrm{f}} x_{2}\right)\right)-\left(1-?_{\mathrm{u} h}\right) \mathrm{W}\left(C\left(\mathrm{u}, h_{\mathrm{u}}, x_{2}\right)\right)\right]+$

$$
\begin{aligned}
& (1-\mathrm{p})\left[?_{\mathrm{f}} \mathrm{W}\left(C\left(\mathrm{f}, 1_{\mathrm{f}}, x_{2}\right)\right)-?_{\mathrm{ul}} \mathrm{W}\left(C\left(\mathrm{u}, \ell_{\mathrm{u}} x_{2}\right)\right)\right]+ \\
& \mathrm{p}\left[\mathrm{W}\left(C\left(\mathrm{f}, x_{1}\right)\right)-\mathrm{W}\left(C\left(\mathrm{u}, x_{1}\right)\right)\right] .
\end{aligned}
$$




$$
\begin{aligned}
& B=\left[Q_{\mathrm{f} h} \mathrm{~W}\left(C\left(\mathrm{f}, h_{\mathrm{f}}, x_{2}\right)\right)-Q_{\mathrm{u} h} \mathrm{~W}\left(C\left(\mathrm{u}, h_{\mathrm{u}}, x_{2}\right)\right)\right]+ \\
& {\left[\left(\mathrm{p}-Q_{\mathrm{ff}}\right) \mathrm{W}\left(C\left(\mathrm{f}, \ell_{\mathrm{f}}, x_{2}\right)\right)-\left(\mathrm{p}-Q_{\mathrm{ul}}\right) \mathrm{W}\left(C\left(\mathrm{u}, \ell_{\mathrm{u}}, x_{2}\right)\right)\right]-\mathrm{p}\left[\mathrm{W}\left(C\left(\mathrm{f}, x_{1}\right)\right)-\mathrm{W}\left(C\left(\mathrm{u}, x_{1}\right)\right)\right] .}
\end{aligned}
$$

A similar exercise establishes that (IC. $\left.m_{\mathrm{u}}\right)$, the incentive constraint of inducing a truthful disclosure of the signal when the manager exerts the good-performance level of effort can be written as:

$-A-\theta_{\mathrm{g}}^{\mathrm{u}} B \geq 0$.

Note that (IC. $\left.m_{\mathrm{u}}\right)$ and (IC. $\left.m_{\mathrm{f}}\right)$ contain the same arguments with opposite signs, because a truthful report of say, good news, is misrepresentation when the signal is unfavorable.

The last incentive constraint is designed to deter double shirking: The manager is induced to disclose the true signal and exert the good-performance level of effort instead of misrepresenting and exerting the poor-performance level of effort,

$\forall s, \quad \mathrm{EW}\left(m, \mathrm{P}, r \mid m=s, a_{\mathrm{g}}\right)=\mathrm{EW}\left(m, \mathrm{P}, r \mid m \neq s, a_{\mathrm{p}}\right)$. $\left(\mathrm{IC} . a m_{s}\right)$

Specifically,

When $s=$,

$$
\begin{aligned}
& {\left[?_{\mathrm{f} h} \theta_{g}^{\mathrm{f}}+(1-\mathrm{p})\left(1-?_{\mathrm{fh}}\right)\left(1-\theta_{g}^{\mathrm{f}}\right)\right] \mathrm{W}\left(C\left(\mathrm{f}, h_{\mathrm{f}}, x_{2}\right)\right)+} \\
& {\left[\left(1-?_{\mathrm{fl}}\right) \theta_{g}^{\mathrm{f}}+(1-\mathrm{p}) ?_{\mathrm{fll}}\left(1-\theta_{g}^{\mathrm{f}}\right)\right] \mathrm{W}\left(C\left(\mathrm{f}, \ell_{\mathrm{f}}, x_{2}\right)\right)+} \\
& \mathrm{p}\left(1-\theta_{g}^{\mathrm{f}}\right) \mathrm{W}\left(C\left(\mathrm{f}, x_{1}\right)\right)-\mathrm{V}\left(a_{\mathrm{g}}\right)= \\
& {\left[?_{\mathrm{u} h} \theta_{\mathrm{p}}^{\mathrm{f}}+(1-\mathrm{p})\left(1-?_{\mathrm{u} h}\right)\left(1-\theta_{\mathrm{p}}^{\mathrm{f}}\right)\right] \mathrm{W}\left(C\left(\mathrm{u}, h_{\mathrm{u}}, x_{2}\right)\right)+} \\
& {\left[\left(1-?_{\mathrm{ul}}\right) \theta_{\mathrm{p}}^{\mathrm{f}}+(1-\mathrm{p}) ?_{\mathrm{ul}}\left(1-\theta_{\mathrm{p}}^{\mathrm{f}}\right)\right] \mathrm{W}\left(C\left(\mathrm{u}, \ell_{\mathrm{u}}, x_{2}\right)\right)+}
\end{aligned}
$$




$$
\mathrm{p}\left(1-\theta_{\mathrm{p}}^{\mathrm{f}}\right) \mathrm{W}\left(C\left(\mathrm{u}, x_{1}\right)\right)-\mathrm{V}\left(a_{\mathrm{p}}\right)
$$

$\left(\mathrm{IC} . a m_{\mathrm{u}}\right)$ is similar.

\section{The reduced program for non-verifiable information:}

We solve first the case where the private signal is non-verifiable. The program can be reduced as follows:

\section{$\underline{\text { Constraints associated with good news }}$}

\section{- $\quad\left(\mathrm{IC} a_{\mathrm{f}}\right)$}

(IC $a_{\mathrm{f}}$ ) is not binding. The proof is by contradiction. If it were

binding, subtracting (IC. $a_{\mathrm{u}}$ ) from (IC. $\left.a_{\mathrm{f}}\right)$ yields:

$$
\begin{aligned}
& B=\left[Q_{\sharp} \mathrm{W}\left(C\left(\mathrm{f}, h_{\mathrm{f}}, x_{2}\right)\right)-Q_{\mathrm{u} h} \mathrm{~W}\left(C\left(\mathrm{u}, h_{\mathrm{u}}, x_{2}\right)\right)\right]+ \\
& {\left[\left(\mathrm{p}-Q_{\mathrm{fl}}\right) \mathrm{W}\left(C\left(\mathrm{f}, \ell_{\mathrm{f}}, x_{2}\right)\right)-\left(\mathrm{p}-Q_{\mathrm{ul}}\right) \mathrm{W}\left(C\left(\mathrm{u}, \ell_{\mathrm{u}}, x_{2}\right)\right)\right]-} \\
& \mathrm{p}\left[C\left(\mathrm{f}, x_{1}\right)-C\left(\mathrm{u}, x_{1}\right)\right]=\frac{\mathrm{V}\left(a_{g}\right)-\mathrm{V}\left(a_{\mathrm{p}}\right)}{\theta_{\mathrm{g}}^{\mathrm{f}}-\theta_{\mathrm{p}}^{\mathrm{f}}}-v<0 .
\end{aligned}
$$

The first inequality holds because while ( $\mathrm{IC} a_{\mathrm{u}}$ ) holds as a weak inequality, (IC $a_{f}$ ), by assumption of the proof, holds as a strict equality. The second inequality follows from our assumption that effort is more productive when the signal is

favorable. Upon adding $\left(\mathrm{IC}_{m_{s}}\right)$ together, we obtain: $\left[\theta_{g}^{\mathrm{f}}-\theta_{g}^{\mathrm{u}}\right] B=0$. This yields the required contradiction because (IC. $m_{s}$ ) imply $B=0$, since, by assumption, $\theta_{g}^{\mathrm{f}}>\theta_{g}^{\mathrm{u}}$.

\section{- $\quad\left(\mathrm{IC} m_{\mathrm{f}}\right)$}

The fact that (IC. $a_{\mathrm{f}}$ ) is not binding implies that either (IC. $\left.m_{\mathrm{f}}\right)$ is binding, or (IC $a m_{\mathrm{f}}$ ) is binding, or both, since, if not, the principal could reduce the expected contract's cost by shifting the reward from when $m=\mathrm{f}$ to when $m=\mathrm{u}$. Suppose, by 
contradiction, that only (IC. $a m_{\mathrm{f}}$ ) is binding. Then, upon subtracting (IC $a m_{\mathrm{f}}$ ) from $\left(\right.$ IC. $\left.m_{\mathrm{f}}\right)$, we obtain:

$$
\begin{aligned}
& {\left[?_{\mathrm{u} h} \theta_{\mathrm{p}}^{\mathrm{f}}+(1-\mathrm{p})\left(1-?_{\mathrm{u} h}\right)\left(1-\theta_{\mathrm{p}}^{\mathrm{f}}\right)\right] \mathrm{W}\left(C\left(\mathrm{u}, h_{\mathrm{u}}, x_{2}\right)\right)+} \\
& {\left[\left(1-?_{\mathrm{ul}}\right) \theta_{\mathrm{p}}^{\mathrm{f}}+(1-\mathrm{p}) ?_{\mathrm{ul}}\left(1-\theta_{\mathrm{p}}^{\mathrm{f}}\right)\right] \mathrm{W}\left(C\left(\mathrm{u}, \ell_{\mathrm{u}}, x_{2}\right)\right)+\mathrm{p}\left(1-\theta_{\mathrm{p}}^{\mathrm{f}}\right) \mathrm{W}\left(C\left(\mathrm{u}, x_{1}\right)\right)-\mathrm{V}\left(a_{\mathrm{g}}\right)=} \\
& {\left[?_{\mathrm{u} h} \theta_{g}^{\mathrm{f}}+(1-\mathrm{p})\left(1-?_{\mathrm{u} h}\right)\left(1-\theta_{g}^{\mathrm{f}}\right)\right] \mathrm{W}\left(C\left(\mathrm{u}, h_{\mathrm{u}}, x_{2}\right)\right)-} \\
& {\left[\left(1-?_{\mathrm{ul}}\right) \theta_{g}^{\mathrm{f}}+(1-\mathrm{p}) ?_{\mathrm{ul}}\left(1-\theta_{g}^{\mathrm{f}}\right)\right] \mathrm{W}\left(C\left(\mathrm{u}, \ell_{\mathrm{u}}, x_{2}\right)\right)-} \\
& \mathrm{p}\left(1-\theta_{g}^{\mathrm{f}}\right) \mathrm{W}\left(C\left(\mathrm{u}, x_{1}\right)\right)-\mathrm{V}\left(a_{\mathrm{p}}\right)>0 .
\end{aligned}
$$

The inequality follows from the assumption of the claim that (IC. $\left.m_{\mathrm{f}}\right)$ is nonbinding while (IC . $\left.a m_{\mathrm{f}}\right)$ is. Rearranging yields:

$$
Q_{\mathrm{u} h} \mathrm{~W}\left(C\left(\mathrm{u}, h_{\mathrm{f}}, x_{2}\right)\right)+\left(\mathrm{p}-Q_{\mathrm{ul}}\right) \mathrm{W}\left(C\left(\mathrm{u}, \ell_{\mathrm{f}}, x_{2}\right)\right)-\mathrm{pW}\left(C\left(\mathrm{u}, x_{1}\right)\right)<\frac{\mathrm{V}\left(a_{g}\right)-\mathrm{V}\left(a_{\mathrm{p}}\right)}{?_{\mathrm{g}}^{\mathrm{f}}-?_{\mathrm{p}}^{\mathrm{f}}}
$$

Since, by assumption, the productivity of effort is higher for a good-news

signal, i.e., $\theta_{g}^{\mathrm{f}}-\theta_{\mathrm{p}}^{\mathrm{f}}>\theta_{g}^{\mathrm{u}}-\theta_{\mathrm{p}}^{\mathrm{u}}$, we obtain that $\frac{\mathrm{V}\left(a_{g}\right)-\mathrm{V}\left(a_{\mathrm{p}}\right)}{?_{\mathrm{g}}^{\mathrm{f}}-?_{\mathrm{p}}^{\mathrm{f}}}<\frac{\mathrm{V}\left(a_{g}\right)-\mathrm{V}\left(a_{\mathrm{p}}\right)}{?_{\mathrm{g}}^{\mathrm{u}}-?_{\mathrm{p}}^{\mathrm{u}}}$

which implies that (A11) contradicts (A4). Hence, (IC. $m_{f}$ ) cannot be non-binding.

- (IC a $a m_{\mathrm{f}}$ )

It is easy to see that this constraint cannot be binding. Had (IC. $a m_{\mathrm{f}}$ ) been binding, then, by the fact that (IC. $m_{\mathrm{f}}$ ) is binding, (A11) would have held as a strict equality, which contradicts (A4). 
Constraints associated with bad news

- $\quad\left(\mathrm{IC} \cdot a_{\mathrm{u}}\right)$

(IC $a_{\mathrm{u}}$ ) must be binding, because if not, the optimal contract is to pay the agent a fixed salary, which violates the manager's incentives to exert effort.

- $\quad\left(\mathrm{IC} a m_{\mathrm{u}}\right)$

(IC $\left.a m_{\mathrm{u}}\right)$ is not binding. Suppose, by contradiction, that (IC. $\left.a m_{\mathrm{u}}\right)$ is binding Subtract it from the binding (IC. $a_{\mathrm{u}}$ ) to obtain:

$$
\begin{aligned}
& {\left[?_{\mathrm{fh}} \theta_{\mathrm{p}}^{\mathrm{u}}+(1-\mathrm{p})\left(1-?_{\mathrm{fh}}\right)\left(1-\theta_{\mathrm{p}}^{\mathrm{u}}\right)\right] \mathrm{W}\left(C\left(\mathrm{f}, h_{\mathrm{f}}, x_{2}\right)\right)+} \\
& {\left[\left(1-?_{\mathrm{fl}}\right) \theta_{\mathrm{p}}^{\mathrm{u}}+(1-\mathrm{p}) ?_{\mathrm{fl}}\left(1-\theta_{\mathrm{p}}^{\mathrm{u}}\right)\right] \mathrm{W}\left(C\left(\mathrm{f}, \ell_{\mathrm{f}} x_{2}\right)\right)+} \\
& \mathrm{p}\left(1-\theta_{\mathrm{p}}^{\mathrm{u}}\right) \mathrm{W}\left(C\left(\mathrm{f}, x_{1}\right)\right)- \\
& {\left[?_{\mathrm{u} h} \theta_{\mathrm{p}}^{\mathrm{u}}+(1-\mathrm{p})\left(1-?_{\mathrm{u} h}\right)\left(1-\theta_{\mathrm{p}}^{\mathrm{u}}\right)\right] \mathrm{W}\left(C\left(\mathrm{u}, h_{\mathrm{u}}, x_{2}\right)\right)-} \\
& {\left[\left(1-?_{\mathrm{ul}}\right) \theta_{\mathrm{p}}^{\mathrm{u}}+(1-\mathrm{p}) ?_{\mathrm{ul}}\left(1-\theta_{\mathrm{p}}^{\mathrm{u}}\right)\right] \mathrm{W}\left(C\left(\mathrm{u}, \ell_{\mathrm{u}}, x_{2}\right)\right)+} \\
& \mathrm{p}\left(1-\theta_{\mathrm{p}}^{\mathrm{u}}\right) \mathrm{W}\left(C\left(\mathrm{u}, x_{1}\right)\right)=0 .
\end{aligned}
$$

Rearranging, yields:

$$
A+\theta_{\mathrm{p}}^{\mathrm{u}} B=0
$$

(A13) contradicts (IC. $m_{\mathrm{u}}$ ), $A+\theta_{g}^{\mathrm{u}} B=0$, (see (A8)), since $B=0$, and $\theta_{g}^{\mathrm{u}}>\theta_{\mathrm{p}}^{\mathrm{u}}$. The fact that $B=0$ is readily proved by adding (A5) and (A8).

\section{- $\quad\left(\mathrm{IC} m_{\mathrm{u}}\right)$}

(IC $m_{\mathrm{u}}$ ) is binding, because, if not, the manager's compensation would have been independent of reported outcome and market price when $m=$ f, i.e., it would have been constant, violating the mana ger's incentives to exert effort when he observes a favorable signal. 


\section{The solution of the program when information is non-verifiable:}

For parsimony, we drop the subscript of $w_{m}$ Denoting a generic element of the contract by $C_{r}^{m w}$, we solve the following reduced program:

$$
\operatorname{maxE}[x]-\mathrm{E}_{s, x, w_{m}}\left[C_{2}^{m w} \mid a_{g}, m=s\right]-\mathrm{E}_{s, x}\left[C_{1}^{m} \mid a_{g}, m=s\right]
$$

s.t.

$$
\mathrm{E}_{s, x, w_{m}}\left[\mathrm{~W}\left(C_{2}^{m w}\right) \mid a_{g}, m=s\right]+\mathrm{E}_{s, x}\left[\mathrm{~W}\left(C_{1}^{m}\right) \mid a_{g}, m=s\right]-\mathrm{V}\left(a_{g}\right) \geq \mathrm{Wo} .
$$

(PC)

$$
\begin{aligned}
& Q_{\mathrm{u} h} \mathrm{~W}\left(C_{2}^{\mathrm{u} h}\right)+\left(\pi-\mathrm{Q}_{\mathrm{u} \ell}\right) \mathrm{W}\left(C_{2}^{\mathrm{u} \ell}\right)-\pi \mathrm{W}\left(C_{1}^{\mathrm{u}}\right)=v^{22} \\
& A+\theta_{\mathrm{g}}^{\mathrm{f}} B=0 .{ }^{23} \\
& A-\theta_{g}^{\mathrm{u}} B=0 .{ }^{24}
\end{aligned}
$$

\section{The equilibrium conditions:}

Denoting by ?, $\mu, ?^{\mathrm{f}}$ and $?^{\mathrm{u}}$, the Lagrange multipliers of (PC), (IC. $\left.a_{\mathrm{u}}\right),\left(\right.$ IC. $\left.m_{\mathrm{f}}\right)$, and (IC. $\left.m_{\mathrm{u}}\right)$, respectively, the first-order-conditions are:

\footnotetext{
${ }^{22}$ See (A4).

${ }^{23}$ See (A5).

${ }^{24}$ See (A8).
} 


$$
\frac{1}{\mathrm{~W}^{\prime}\left(C_{2}^{\mathrm{f} h}\right)}=\lambda+\frac{1}{\gamma} ?^{\mathrm{f}}-\frac{\mathrm{Z}\left(\mathrm{u} h_{\mathrm{u}}\right)}{\gamma \mathrm{Z}\left(\mathrm{f} h_{\mathrm{f}}\right)} ?^{\mathrm{u}}
$$

$\frac{1}{\mathrm{~W}^{\prime}\left(C_{2}^{\mathrm{f} \ell}\right)}=\lambda+\frac{1}{\gamma} ?^{\mathrm{f}}-\frac{\mathrm{Y}\left(\mathrm{u} \ell_{\mathrm{u}}\right)}{\gamma \mathrm{Y}\left(\mathrm{f} \ell_{\mathrm{f}}\right)} ?^{\mathrm{u}}$.

$\frac{1}{\mathrm{~W}^{\prime}\left(C_{1}^{\mathrm{f}}\right)}=\lambda+\frac{1}{\gamma} ?^{\mathrm{f}}-\frac{1-\theta_{\mathrm{g}}^{\mathrm{u}}}{\gamma\left(1-\theta_{\mathrm{g}}^{\mathrm{f}}\right)} ?^{\mathrm{u}}$

$\frac{1}{\mathrm{~W}^{\prime \prime}\left(C_{2}^{\mathrm{u} h}\right)}=\lambda+\frac{Q_{\mathrm{u}}}{(1-\gamma) \mathrm{Z}(\mathrm{u})} \mu-\frac{\mathrm{Z}\left(\mathrm{f} h_{\mathrm{f}}\right)}{(1-\gamma) \mathrm{Z}\left(\mathrm{u} h_{\mathrm{u}}\right)} ?^{\mathrm{f}}+\frac{1}{1-\gamma} ?^{\mathrm{u}}$

$\frac{1}{\mathrm{~W}^{\prime}\left(C_{2}^{\mathrm{u} \ell}\right)}=\lambda+\frac{\mathrm{p}-Q_{\mathrm{u}}}{(1-\gamma) \mathrm{Y}(\mathrm{u})} \mu-\frac{\mathrm{Y}\left(\mathrm{f} \ell_{\mathrm{f}}\right)}{(1-\gamma) \mathrm{Y}\left(\mathrm{u} \ell_{\mathrm{u}}\right)}{ }^{\mathrm{f}}+\frac{1}{1-\gamma} ?^{\mathrm{u}}$

$\frac{1}{\mathrm{~W}^{\prime}\left(C_{1}^{\mathrm{u}}\right)}=\lambda-\frac{1}{(1-\gamma)\left(1-\theta_{\mathrm{g}}^{\mathrm{u}}\right)} \mu-\frac{1-\theta_{\mathrm{g}}^{\mathrm{f}}}{(1-\gamma)\left(1-\theta_{\mathrm{g}}^{\mathrm{u}}\right)} ?^{\mathrm{f}}+\frac{1}{1-\gamma} ?^{\mathrm{u}}$

where: $\mathrm{Z}\left(m w_{m}\right)=\theta_{\mathrm{g}}^{S} ?_{m w}+(1-\mathrm{p})\left(1-\theta_{\mathrm{g}}^{S}\right)\left(1-?_{m w}\right) ; \mathrm{Y}\left(m w_{m}\right)=\theta_{\mathrm{g}}^{S}\left(1-?_{m w}\right)+$

$(1-\mathrm{p})\left(1-\theta_{\mathrm{g}}^{S}\right) ?_{m w}, m=s=\mathrm{u}, \mathrm{f}, w=h_{m}, 1_{m}$

The first-order conditions of the reduced program show that the payments to the manager differ across signals. Since a contract that is independent of the signal is feasible, this implies that disclosure reduces the cost of the manager's incentives. 
Numerical examples:

Let $?_{m}=0.8$ for all disclosures, $\mathrm{p}=0.75, \gamma=0.5, \theta_{\mathrm{g}}^{S}=0.8$ when $s=\mathrm{f}$ and 0.5 when

$s=\mathrm{u} ; \theta_{\mathrm{p}}^{s}=0.6$ when $\mathrm{s}=\mathrm{f}$ and 0.4 when $s=u, \mathrm{~W}(\mathrm{z})=\mathrm{z}^{1 / 2} ; \mathrm{V}\left(a_{\mathrm{g}}\right)=0.75, \mathrm{~V}\left(a_{\mathrm{p}}\right)=0$, and

$\mathrm{Wo}=9.25$.

The equilibrium contract is: $C_{2}^{\mathrm{f} h}=169, C_{2}^{\mathrm{f} \ell}=123.65, C_{1}^{\mathrm{f}}=9, C_{2}^{\mathrm{u} h}=183.87$,

$C_{2}^{\mathrm{u} \ell}=78.85, C_{1}^{\mathrm{u}}=12.67 . \mathrm{E}[\mathrm{C}]=117.3$. A contract with the same parameters as above

that is independent of $m$ features: $C_{2}^{h}=176.39, C_{2}^{\ell}=100, C_{1}=10.77$, with an expected cost of $117.637>117.3$.

The reduced program when the information is verifiable

We now consider the case when the information is verifiable. Here, the principal can elicit the truth costlessly by imposing a penalty on misrepresentation.

Denoting the penalty by $\mathrm{t}^{\mathrm{s}},\left(\mathrm{IC} . m_{s}\right)$ are:

$\forall s$,

$\mathrm{EW}\left(m, \mathrm{P}, r \mid m=s, a_{\mathrm{g}}\right)=\mathrm{EW}\left(m, \mathrm{P}, r \mid m \neq s, a_{\mathrm{g}}\right)-\mathrm{t}^{\mathrm{s}}$.

$\left(\mathrm{IC} . m_{s}\right)$

Since the agent is not protected by limited liability, the principal can set $\mathrm{t}^{\mathrm{s}}$ at as high a level as he desires. In particular, if there exists a $\mathrm{t}^{\mathrm{s}}$, say $\mathrm{t}^{\mathrm{s} *}$, that makes the agent indifferent between disclosing the truth and misrepresenting (i.e., (IC. $m_{s}$ ) hold as strict equalities), then, the principal can increase the penalty and thus relax the constraints.

A similar argument establishes that $\left(\mathrm{IC} a m_{s}\right)$ are not binding. 


\section{The solution of the verifiable information case}

The principal designs the truth-inducing contract by solving the following

program:

$$
\operatorname{maxE}[x]-\mathrm{E}_{s, x, w_{m}}\left[C_{2}^{m w} \mid a_{g}, m=s\right]-\mathrm{E}_{s, x}\left[C_{1}^{m} \mid a_{g}, m=s\right]
$$

s.t.

$\mathrm{E}_{s, x, w_{m}}\left[\mathrm{~W}\left(C_{2}^{m w}\right) \mid a_{g}, m=s\right]+\mathrm{E}_{s, x}\left[\mathrm{~W}\left(C_{1}^{m}\right) \mid a_{g}, m=s\right]-\mathrm{V}\left(a_{g}\right) \geq \mathrm{Wo}$.

$$
\begin{array}{ll}
Q_{\mathrm{u} h} \mathrm{~W}\left(C_{2}^{\mathrm{u} h}\right)+\left(\mathrm{p}-\mathrm{Q}_{\mathrm{u} \ell}\right) \mathrm{W}\left(C_{2}^{\mathrm{u} \ell}\right)-\mathrm{pW}\left(C_{1}^{\mathrm{u}}\right)=v . & \left(\text { IC } \cdot a_{\mathrm{u}}\right) \\
Q_{\mathrm{f} h} \mathrm{~W}\left(C_{2}^{\mathrm{f} h}\right)+\left(\mathrm{p}-\mathrm{Q}_{\mathrm{f} \ell}\right) \mathrm{W}\left(C_{2}^{\mathrm{f} \ell}\right)-\mathrm{pW}\left(C_{1}^{\mathrm{f}}\right)=v . & \left(\text { IC } a_{\mathrm{f}}\right)
\end{array}
$$

Denoting by $\mu^{\mathrm{s}}$ the Lagrange multiplier of (IC. $a_{\mathrm{s}}$ ), the first-order conditions

are:

$$
\begin{aligned}
& \frac{1}{\mathrm{~W}^{\prime}\left(C_{2}^{\mathrm{f} h}\right)}=?+\frac{Q_{\mathrm{f}}}{\gamma \mathrm{Z}(\mathrm{f})} \mu^{\mathrm{f}} . \\
& \frac{1}{\mathrm{~W}^{\prime}\left(C_{2}^{\mathrm{f} \ell}\right)}=\lambda+\frac{\pi-Q_{\mathrm{f}}}{\gamma \mathrm{Y}(\mathrm{f})} \mu^{\mathrm{f}} . \\
& \frac{1}{\mathrm{~W}^{\prime}\left(C_{1}^{\mathrm{f}}\right)}=\lambda-\frac{1}{\gamma\left(1-\theta_{\mathrm{g}}^{\mathrm{f}}\right)} \mu^{\mathrm{f}} . \\
& \frac{1}{\mathrm{~W}^{\prime}\left(C_{2}^{\mathrm{u} h}\right)}=\lambda+\frac{Q_{\mathrm{u}}}{(1-\gamma) \mathrm{Z}(\mathrm{u})} \mu^{\mathrm{u}} . \\
& \frac{1}{\mathrm{~W}^{\prime}\left(C_{2}^{\mathrm{u} \ell}\right)}=\lambda+\frac{\mathrm{p}-Q_{\mathrm{u}}}{(1-\gamma) \mathrm{Y}(\mathrm{u})} \mu^{\mathrm{u}} .
\end{aligned}
$$




$$
\frac{1}{\mathrm{~W}^{\prime}\left(C_{1}^{\mathrm{u}}\right)}=\lambda-\frac{1}{(1-\gamma)\left(1-\theta_{g}^{u}\right)} \mu^{\mathrm{u}}
$$

It is readily seen that both $\mu^{\mathrm{f}}$ and $\mu^{\mathrm{u}}$ are binding, because if not, the compensation will be a flat wage that fails to induce the higher level of effort. Hence, the payments differ across the signals.

Numerical example:

Let the parameters be as in the above. When the manager is induced to disclose the truth, his payment schedule is: $C_{2}^{\mathrm{f} h}=119.63, C_{2}^{\mathrm{f} \ell}=100, C_{1}^{\mathrm{f}}=35.25$, $C_{2}^{\mathrm{u} h}=215.72, C_{2}^{\mathrm{u} \ell}=100, C_{1}^{\mathrm{u}}=21.98 . \mathrm{E}[\mathrm{C}]=111.49$. As shown above, the expected cost of a contract that is independent of $m$ is $117.64>111.49$.

$\underline{\text { Part (b): }}$

By the separability between expected contract's cost and expected gross liquidating dividends, part (b) is a corollary to part (a). Q.E.D.

\section{Proof of Proposition 1:}

Since the information of the manager is verifiable, either the firm discloses the truth or it does not disclose. By Lemma 1, the value of a firm that is induced to disclose the truth is strictly higher than that of a firm that does not. Hence, a truthinducing contract is desirable for both PMO and VMO. A TTBN is supported by the market maker interpreting the off-equilibrium move of non-disclosure as an attempt to conceal bad news. Q.E.D. 


\section{Proof of Proposition 2:}

\section{The game}

The game includes four players. Table 4 summarizes their strategies and objective functions, given our assumptions:

Insert Table 4 about here.

\section{Perfect Bayesian Nash Equilibrium}

Perfect Bayesian Nash equilibrium in our study is the profile of actions of all players, and the beliefs of the market maker about the firm's owners' type, $\mathrm{O}$, and signal, $s$. The equilibrium is the following vector,

$\left\{\left(C^{\mathrm{VMO}}(),. C^{\mathrm{PMO}}(),. \mathrm{a}^{\mathrm{PMO}}\right),\left(m\left(C^{\mathrm{VMO}}().\right), a\left(C^{\mathrm{VMO}}().\right), m\left(C^{\mathrm{PMO}}().\right), a\left(C^{\mathrm{PMO}}().\right)\right),\left(\mathrm{P}\left(m, w_{m}\right)\right.\right.$, $\left.\{\operatorname{Pr}(\mathrm{O}, s \mid m)\}_{\mathrm{O}=\mathrm{VMO}, \mathrm{PMO}, s=\mathrm{u}, \mathrm{f}}\right\}$.

In words: the equilibrium describes the strategies of the owners, the manager, and the market-maker and the beliefs of the market-maker.

- Each owner's type designs the manager's contract, $C^{\mathrm{O}}, \mathrm{O}=\mathrm{VMO}, \mathrm{PMO}$, and PMO choose the date of exit, $\mathrm{a}^{\mathrm{PMO}}$;

- the contract induces the manager's disclosure, $m$, and effort, $a$, according to the type of contract designers;

- the market-maker sets the price, $\mathrm{P}\left(m, w_{m}\right)$, and updates beliefs on types, where it is common knowledge that he faces either one of four types, with the following prior distribution:

1. A PM-firm with good news, with prior probability of $\gamma(1-d)$.

2. A PM-firm with bad news, with prior probability of $(1-\gamma)(1-d)$.

3. A VM-firm with good news, with prior probability of $\gamma \mathrm{d}$.

4. A VM-firm with bad news, with prior probability of $(1-\gamma) \mathrm{d}$. 
$\underline{\text { The operational definition }}$

Since the managers are the agents of the owners ${ }^{25}$, we can, without loss of generality, analyze the game between the firms and the market-maker as a game between owners and the market-maker,. In essence then, we study a signaling game. The owners are the sender, the signal is the voluntary disclosure, and the receiver is the market-maker.

By Definition 8.1. of Fudenberg and Tirole (p. 325-326) of perfect Bayesian equilibrium in signaling games, we are looking for a profile of actions that satisfies the following (P1), (P2,), and (B) requirements:

(P1) for each type of owners, $\mathrm{O}, \mathrm{O}=\mathrm{VMO}, \mathrm{PMO}$, the equilibrium strategy is best response.

Since VMO maximize the expected Date-5 liquidating dividends, by Lemma 1 , they will design a truth-inducing contract, i.e., $C^{\mathrm{VMO}}=C\left(m, w_{m}, \eta \mid m=s\right)$.

PMO make two decisions. On Date 3, PMO decide whether to stay or sell:
$\mathrm{a}^{\mathrm{PMO}}=\left\{\begin{array}{l}0 \\ 1\end{array}\right.$
if

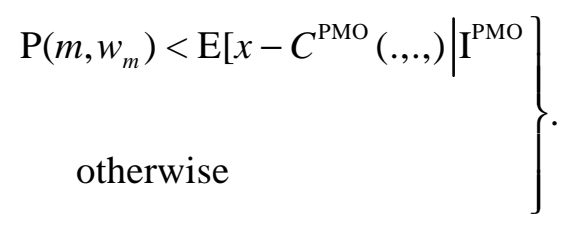

In words: PMO stay until Date 5 only if, conditional on their information set, the market-price understates the expected Date-5 liquidating dividend.

On Date 1, PMO design the contract by solving the following program:

\footnotetext{
${ }^{25}$ In game theory jargon, they are the Stackelberg followers of the owners.
} 


$$
\begin{aligned}
& \max _{C^{\mathrm{O}}(.)} \mathrm{E}\left[\mathrm{W}_{1}^{\mathrm{PMO}}\right]=\mathrm{E}_{w, s}\left[\mathrm{~W}_{3}^{\mathrm{PMO}}\right]= \\
& \mathrm{E}_{w, s}\left[\mathrm{a}^{\mathrm{PMO}}+\left(1-\mathrm{a}^{\mathrm{PMO}}\right) \mathrm{E}\left(x-C^{\mathrm{PMO}} \mid \mathrm{I}^{\mathrm{PMO}}\right] .\right. \\
& \text { s.t. } \\
& \mathrm{E}\left[\mathrm{W}\left(C^{\mathrm{PMO}}(.)\right)\right]-\mathrm{V}\left(a_{\mathrm{g}}\right)=\text { Wo. } \\
& \forall s, \quad \begin{array}{l}
\quad s \in\left\{a_{\mathrm{p}}, a_{\mathrm{g}}\right\} \\
\left(a_{\mathrm{g}}, m\right) \in \operatorname{Ergmax} \\
\quad m \in\{\mathrm{u}, f\} \cup\{\varnothing\}
\end{array}
\end{aligned}
$$

(P2) The market-maker sets the price that yields zero expected profits given his beliefs on the firm's type.

Since the market-maker's objective is to make zero profits, (P2) implies that he sets the Date-3 price to the level of the expected Date-5 liquidating dividends, conditional on his beliefs on the firm's type.

(B) The beliefs of the market-maker are derived from the strategies of the owners via Bayes' rule when he observes a disclosure that is an equilibrium for at least one type. If the disclosure is not prescribed by any type, any beliefs are permissible.

This requirement implies that the market-maker cannot ignore the disclosure because he knows that VMO design a truth-inducing contract, and hence, disclosure is informative even if a signal is noisy because PM firms, which do not disclose the truth, send the same signal.

\section{$\underline{\text { The equilibrium }}$}

By the above discussion, we have reduced the strategic form of the game. We discarded the strategy of a non-truth-inducing contract for the VMO and the strategy 
of ignoring disclosure by the market-maker. We now discard the alternatives of designing a bad-news disclosure strategy or a non-disclosure strategy by PMO.

PMO will design neither a bad-news contract nor a non- disclosure contract. Suppose, by contradiction, that they design a bad-news disclosure contract. Then, by (B), the posterior beliefs of the market-maker are:

$\operatorname{Prob}[$ VM firm with $s=\mathrm{f} \mid m=\mathrm{f}]=1$.

Prob[VM firm with $s=\mathrm{u} \mid m=\mathrm{u}]=\frac{\mathrm{d}(1-?)}{\mathrm{d}(1-?)+(1-\mathrm{d})}$.

$\operatorname{Prob}[\mathrm{PM}$ firm with $s=\mathrm{f} \mid m=\mathrm{u}]=\frac{(1-\mathrm{d}) ?}{\mathrm{~d}(1-?)+(1-\mathrm{d})}$.

$\operatorname{Prob}[\mathrm{PM}$ firm with $s=\mathrm{u} \mid m=\mathrm{u}]=\frac{(1-\mathrm{d})(1-?)}{\mathrm{d}(1-?)+(1-\mathrm{d})}$

In words: the market-maker believes that good-news is the truth for a VM firm. He forms a probability distribution over the remaining types upon bad-news disclosure.

By (P2), the market-maker, who wishes to make zero profits, sets the price as follows:

If $m=\mathrm{f}, \mathrm{P}\left(\mathrm{f}, w_{\mathrm{f}}\right)=\mathrm{A}\left(w_{\mathrm{f}}\right)$.

If $m=\mathrm{u}$,

$\mathrm{P}\left(\mathrm{u}, w_{\mathrm{u}}\right)=\frac{\mathrm{d}(1-?)}{\mathrm{d}(1-?)+(1-\mathrm{d})} \mathrm{E}\left[x-C \mid s=\mathrm{u}, w_{\mathrm{u}}\right]+\frac{1-\mathrm{d}}{\mathrm{d}(1-?)+(1-\mathrm{d})} \mathrm{B}\left(w_{\mathrm{u}}\right)$.

Since, however, by Definition 3 of good news, $\mathrm{E}\left[x-C \mid s=\mathrm{u}, w_{\mathrm{u}}\right]<\mathrm{A}\left(w_{\mathrm{f}}\right)$, and by Lemma 1 and Definition 3, $\mathrm{B}\left(w_{\mathrm{f}}\right)<\mathrm{A}\left(w_{\mathrm{f}}\right)$ [see rigorous proof below], designing a bad-news contract violates requirement (P1) of PBE, since PMO are better off designing a good-news disclosure contract. ${ }^{26}$

\footnotetext{
${ }^{26}$ This proof is a fine example for showing that the calculation of Nash equilibrium is a two-stage
} 
A similar proof establishes that a non-disclosure contract will not be designed in equilibrium by PMO. Suppose, by contradiction, that they design a non-disclosure disclosure contract. Then, by (B), the posterior beliefs of the market-maker are:

$\operatorname{Prob}[\mathrm{VM}$ firm with $s=\mathrm{f} \mid m=\mathrm{f}]=1$.

$\operatorname{Prob}[\mathrm{VM}$ firm with $s=\mathrm{u} \mid m=\mathrm{u}]=1$.

$\operatorname{Prob}[\mathrm{PM}$ firm with $s=f \mid m=\varnothing]=\gamma$.

$\operatorname{Prob}[\mathrm{PM}$ firm with $s=\mathrm{u} \mid m=\varnothing]=1-\gamma$.

By (P2), the market-maker, who wishes to make zero profits, sets the price as follows:

If $m=\mathrm{f}, \mathrm{P}\left(\mathrm{f}, w_{\mathrm{f}}\right)=\mathrm{A}\left(w_{\mathrm{f}}\right)$.

If $m=\mathrm{u}, \mathrm{P}\left(\mathrm{u}, w_{\mathrm{u}}\right)=\mathrm{E}\left[x-C^{\mathrm{VMO}} \mid s=\mathrm{u}, w_{\mathrm{u}}\right]$

If $m=\varnothing, \mathrm{P}\left(\varnothing, w_{\varnothing}\right)=\mathrm{B}\left(w_{f}\right)$.

As we shall show below, $\mathrm{B}\left(w_{f}\right)<\mathrm{A}\left(w_{f}\right)$. Hence, designing a bad-news contract violates requirement $(\mathrm{P} 1)$ of $\mathrm{PBE}$, since $\mathrm{PMO}$ are better off deviating to designing a good-news disclosure contract.

The reduced strategic form of the game consists of a matrix (Table 5 below), wherein PMO are the row player, the market maker is the column player, and VMO

procedure. First, we identify the best-response function of each player; and, second, we examine if each action in a candidate equilibrium strategies profile is a best response. Osborne and Rubinstein (1994, p. 15) state:

This ... formulation of the definition points us to a ...method of finding Nash equilibria: first, calculate the best response function of each player (denoted $\mathrm{B}_{\mathrm{i}}\left(a^{*}{ }_{-\mathrm{i}}\right)$ ), then find a profile of $a^{*}$ (explanation: $a^{*}$ is the vector of equilibrium actions of all players in an $\mathrm{N}$ player game, $\left.a^{*}=a{ }_{1}^{*}, a_{2}^{*}, \ldots a^{*}{ }_{\mathrm{i}}, \ldots, a^{*}{ }_{\mathrm{N}}\right)$ for which $a^{*} \in \mathrm{B}_{\mathrm{i}}\left(a_{-\mathrm{i}}^{*}\right)$ for all $\mathrm{i} \in \mathrm{N}$. [explanations in parentheses are added.] 
are the matrix player. The best response of PMO and the market-maker is denoted by and $\bullet$, respectively.

$$
\text { Insert Table } 5 \text { about here. }
$$

As Table 5 shows, the only configuration that is best response for both in pure strategies is in the cell where PMO design a good-news disclosure contract and sell on Date 3 and the market maker believes bad news and discounts good news.

Equation (2) in Proposition 2 is the Bayesian update of the value of a firm given that it discloses good news. When good news is disclosed, the market-maker knows that with conditional probability $\gamma \mathrm{d} /(\gamma \mathrm{d}+(1-\mathrm{d}))$ it is truthful because the contract designers are $\mathrm{VMO}$ (and thus the value of firm equals $\mathrm{A}\left(w_{f}\right)$ ), and that with probability $(1-d) /(\gamma d+(1-d))$ the contract designers are PMO and the disclosure is uninformative, so that the value of the firm equals $\mathrm{B}\left(w_{\mathrm{f}}\right)<\mathrm{A}\left(w_{\mathrm{f}}\right)$.

The price upon non-disclosure

The market-maker faces four types:

1. PM firm with good news.

2. PM firm with bad news.

3. VM firm with good news.

4. VM firm with bad news.

Because the PMO design a good-news disclosure contract, the off-equilibrium price cannot exceed the good-news disclosure price, because a higher non-disclosure price induces PMO to deviate unilaterally to a non- disclosure contract, i.e.,

$\mathrm{P}\left(\varnothing, w_{\varnothing}\right)=\mathrm{P}\left(\mathrm{f}, w_{\mathrm{f}}\right)$. 
Because the market-maker knows that the firm's value cannot be lower than its value for bad news, the minimum non-disclosure price is bounded from below by type 2's and type 4's value,

$$
\mathrm{P}\left(\varnothing, w_{\varnothing}\right)=\min \left\{\mathrm{E}[x-C(w \varnothing, r)], \mathrm{P}\left(\mathrm{u}, w_{\mathrm{u}}\right)\right\} .
$$

By condition (B) of the PBE, we can assign any beliefs to the market-maker upon non-disclosure. ${ }^{27}$ Hence, any price between the good-news price and the badnews value is justifiable by some belief that assigns probability less than one to types 2 and 4.

Note that refinements based on forward induction cannot be used to reduce the off-equilibrium beliefs. Fudenberg and Tirole (1991, p. 447) who discuss the refinements to signaling games that are based on treating an off-equilibrium move as an informative event rather than an arbitrary mistake, state:

..."the solutions suppose that the players are quite sure of the way their opponents will play along the equilibrium path, but that the players are less sure of the off-play. Thus, if player 1 [i.e., the sender] deviates from the equilibrium, player 2 [i.e., the receiver] tries to "explain" the deviation by asking which types of player 1 could do better by making this deviation, if it is met with some response that is "reasonable" ..., than by sticking with the equilibrium strategy followed by the equilibrium response." [An explanation in brackets is added.]

In our study, PMO are strictly worse off deviating when the price is lower than the good-news price and derive the same utility when the off-equilibrium price and

\footnotetext{
${ }^{27}$ Fudenberg and Tirole (1991 p. 326). "Note that if a1 (an action of the sender) is not part of player 1 's (the sender) optimal strategy for some type, observing a1 is a probability-0 event, and Bayes' rule does not pin down posterior beliefs. Any posterior beliefs... are then admissible, and so any action a2 (by the receiver) can be played that is a best response for some beliefs. [Explanations in parentheses are added.]
} 
the good-news disclosure price are the same. Hence, they are not better-off deviating. VMO cannot improve their payoffs by deviating to non- disclosure because they plan to stay until Date 5, and they arrange their relationship with the manager through a binding contract. ${ }^{28}{ }^{29}$

We conclude the proof with showing that the market maker discounts good news.

The proof that the market maker discounts good news, i.e., $\mathrm{A}\left(w_{f}\right)>$ $\mathrm{B}\left(w_{\mathrm{f}}\right)=\mathrm{B}\left(w_{\varnothing}\right)$, follows from the following inequalities:

By the definition of good news,

For $w_{m}=\left\{\left\{1_{m}\right\},\left\{h_{m}\right\}\right\}$, $\mathrm{E}\left[x-C^{*} \mid \mathrm{f}, w_{\mathrm{f}}\right]>\mathrm{E}\left[x-C^{*} \mid \mathrm{u}, w_{\mathrm{u}}\right]=\mathrm{P}\left(s=\mathrm{u}, w_{\mathrm{u}}\right)$.

By Lemma 1, a truth-inducing contract is less costly, hence:

For $w_{m}=\left\{\left\{1_{m}\right\}\right\},\left\{\left\{h_{m}\right\}\right\}$, $\gamma \mathrm{E}\left[x-C^{*} \mid m=s=\mathrm{f}, w_{\mathrm{f}}\right]+(1-\gamma) \mathrm{E}\left[x-C^{*} \mid m=s=\mathrm{u}, w_{\mathrm{u}}\right]>$

${ }^{28}$ Were the VMO to consider a sale on Date 3, then the non-disclosure must be interpreted as bad news, because if not, they would have induced their managers to non-disclose when the news is bad, and sold at an inflated price.

${ }^{29}$ We can show that partial disclosure satisfies the truth-inducing program. That is, type 3 is VMO that induce truth-telling of bad news and silence or honest disclosure of good news. Type 4 is VMO that induce truth-telling of good news, and silence or honest disclosure of bad news. Hence, neither type 3 nor type 4 is better off with non-disclosure.

We do not consider a partial disclosure contract because it is not trembling-hand-perfect: when the contract allows for non-disclosure of, say, good news only, the principal might pay the agent as if the news is good when he is silent, where, by a trembling-hand mistake, the agent did not disclose bad news. [To illustrate, let the parameters be as in the numerical examples above. If the manager does not disclose when the news is bad, he is overpaid by: $0.425[169-183.87]+0.2[123.65-78.85]+0.375[9-$ $12.67]=1.264>0$. 


$$
\mathrm{E}\left[x-C^{*} \mid m=\varnothing, w \varnothing\right]=\mathrm{B}(w \varnothing) .
$$

(A14) and (A15) imply:

$$
\begin{aligned}
\mathrm{A}\left(w_{\mathrm{f}}\right)= & \mathrm{E}\left[x-\mathrm{C}^{*} \mid \mathrm{f}, w_{\mathrm{f}}\right]>\gamma \mathrm{E}\left[x-C^{*} \mid m=s=\mathrm{f}, w_{\mathrm{f}}\right]+(1-\gamma) \mathrm{E}\left[x-C^{*} \mid m=s=\mathrm{u}, w_{\mathrm{u}}\right]> \\
& \mathrm{E}\left[x-\mathrm{C}^{*} \mid \varnothing, w_{\varnothing}\right]=\mathrm{B}\left(w_{\varnothing}\right) .
\end{aligned}
$$

Q.E.D.

\section{Proof of Observation 2}

Table 6 summarizes the expected litigation incidence and cost given that the rational market-maker responds to the disclosure strategies of both PMO and VMO by updating the prior by Bayes' rule, whenever possible.

\section{Insert Table 6 about here.}

Non-disclosure of both good and bad news:

1) Non-disclosure of either good or bad news is not actionable. See the discussion in the paper.

Disclosure:

Rule 10b-5 applies to two instances:

Buyers sue when: $\mathrm{P}\left(\mathrm{f}, h_{\mathrm{f}}\right)>\mathrm{P}\left(\mathrm{u}, h_{\mathrm{u}}\right)$ upon a low-outcome report, $r=x_{1}$. Sellers sue when $\mathrm{P}\left(\mathrm{u}, 1_{\mathrm{u}}\right)<\mathrm{P}\left(\mathrm{f}, 1_{\mathrm{f}}\right)$ upon a high-outcome report, $r=x_{2}$.

We denote the expected litigation costs vis - a-vis buyers (sellers) by $\mathrm{D}^{\mathrm{f}}\left(\mathrm{D}^{\mathrm{u}}\right)$

\section{$\underline{\text { PMO design a truth-inducing contract }}$}

2) VMO design a good-news disclosure contract, the market-maker sets the following prices:

$\mathrm{P}\left(\mathrm{f}, w_{\mathrm{f}}\right)=\frac{?(1-\mathrm{d})}{?(1-\mathrm{d})+\mathrm{d}} \mathrm{A}\left(w_{\mathrm{f}}\right)+\frac{\mathrm{d}}{?(1-\mathrm{d})+\mathrm{d}} \mathrm{B}\left(w_{\mathrm{f}}\right)$, 
$\mathrm{P}\left(\mathrm{u}, w_{\mathrm{u}}\right)=\mathrm{E}\left[x-C\left(m, w_{\mathrm{u}}, r\right) \mid s=\mathrm{u}, w_{\mathrm{u}}\right]$,

where $\mathrm{A}\left(w_{f}\right)$ and $\mathrm{B}\left(w_{f}\right)$ were defined in Proposition 2. $\left[\mathrm{A}\left(w_{\mathrm{f}}\right)\right.$ is the value of a firm with good news, while $\mathrm{B}\left(w_{f}\right)$ equals the expected liquidating dividends of a firm whose manager is not induced to disclose the truth.]

In words: If good news is disclosed, the market-maker knows that with

probability $\frac{?(1-d)}{?(1-d)+d}$ it is truthful because a PM-firm with good news made the disclosure, and with probability of $\frac{\mathrm{d}}{?(1-\mathrm{d})+\mathrm{d}}$ it is not informative because the discloser is a VM firm. If bad news is disclosed, the market maker believes it, knowing that the discloser is a PM firm with bad news.

This equilibrium resembles the one in Proposition 2, where we replace d-the proportion of VM firms- - with 1- $d$ - the proportion of PM firm.

Since we have not ruled out the possibility that the price for good news is lower than the price for bad news, consider what happens under either candidate equilibrium scenario. ${ }^{30}$ Either $\mathrm{P}\left(\mathrm{f}, h_{\mathrm{f}}\right)>\mathrm{P}\left(\mathrm{u}, h_{\mathrm{u}}\right)$ and buyers sue when the firm reports the low outcome, $x_{1}$, or $\mathrm{P}\left(\mathrm{f}, h_{\mathrm{f}}\right)=\mathrm{P}\left(\mathrm{u}, h_{\mathrm{u}}\right)$ and buyers cannot allege that the price they paid was inflated, i.e., the litigation cost is zero.

3) When VMO design a bad-news disclosure contract, the market-maker sets the prices as follows:

$$
\begin{aligned}
& \mathrm{P}\left(\mathrm{f}, w_{\mathrm{f}}\right)=\mathrm{A}\left(w_{\mathrm{f}}\right) \\
& \mathrm{P}\left(\mathrm{u}, w_{\mathrm{u}}\right)=\frac{(1-?)(1-\mathrm{d})}{(1-?)(1-\mathrm{d})+\mathrm{d}} \mathrm{E}\left[x-C\left(m, w_{\mathrm{u}}, r\right) \mid s=\mathrm{u}, w_{\mathrm{u}}\right]+\frac{\mathrm{d}}{(1-?)(1-\mathrm{d})+\mathrm{d}} \mathrm{B}\left(w_{\mathrm{u}}\right)<\mathrm{P}\left(\mathrm{f}, w_{\mathrm{f}}\right) .
\end{aligned}
$$

In words: the market maker trusts good-news disclosure since it reveals a PM

\footnotetext{
${ }^{30} \mathrm{~d}$ exceeding $\overline{\mathrm{d}}$ guarantees that the good-news price exceeds the bad-good price in Proposition 2.
} 
firm with good news. When the firm discloses bad news, however, he knows that

with probability $\frac{(1-?)(1-\mathrm{d})}{(1-?)(1-\mathrm{d})+\mathrm{d}}$ it is a truthful disclosure by a PM firm and with

probability $\frac{\mathrm{d}}{(1-?)(1-\mathrm{d})+\mathrm{d}}$ the discloser is a VM firm for which the disclosure is non-

informative.

By the definition of good news, and by Lemma $1, \mathrm{P}\left(\mathrm{f}, w_{\mathrm{f}}\right)>\mathrm{P}\left(\mathrm{u}, w_{\mathrm{u}}\right)$. Hence, sellers can sue when the market-demand is low and the firm reports the higher outcome, $x_{2}$.

$\underline{\text { PMO do not design a truth-inducing contract }}$

4) When all firms make good-news disclosure, the market maker knows that this disclosure is non-informative, i.e., $\mathrm{P}\left(\mathrm{f}, w_{\mathrm{f}}\right)=\mathrm{B}\left(w_{\mathrm{f}}\right)$. But the buyers can sue for damages when the demand is high and the firm reports $x_{1}$. They face the challenge of establishing at court what the price would have been had the firm disclosed bad news instead of good news (a hypothetical price that needs to be estimated), where the fact that it is common knowledge that some firms do possess bad news may help them in establishing the defendants' liability. Note the difference between this case and the 'always misrepresent' policy: Under 'always misrepresent' the disclosure is not considered false because all participants understand correctly what the firm's disclosure means. Under always good-news disclosure, however, the disclosure can be construed as misleading the market, and the buyers can allege that the firm deliberately hid its bad news.

5) Litigation cost is zero. The market maker sets the same price for the publicly observable good- and bad-news disclosures, since both convey the same information, i.e., $\mathrm{P}\left(\mathrm{f}, w_{\mathrm{f}}\right)=\mathrm{P}\left(\mathrm{u}, w_{\mathrm{u}}\right)=\mathrm{B}\left(w_{\mathrm{u}}\right)$. Hence, no damages 
accrue to either buyers or sellers.

6) The argument mirrors that of (4), where the claimants are the sellers.

Q.E.D.

\section{Proof of Theorem 2:}

By Observation 2, VMO compare a truth-inducing contract with a nondisclosure contract. The difference between a truth-inducing contract and a nondisclosure contract is the savings in the cost of payment to the manager (under truthinducing contract) less the savings in the expected litigation cost (under a nondisclosure contract). Q.E.D.

\section{Proof of Theorem 3:}

We consider seven possible pure-strategy disclosure strategies:

(1) Fully revealing truth-telling ( $m=s, s \in\{\mathrm{u}, \mathrm{f}\})$.

(2) Truth-telling disclosure only of a favorable signal (if $s=\mathrm{f}, m=\mathrm{s}$, and if $s=u$, $m \in\{\varnothing\})$

(3) Truth-telling disclosure only of an unfavorable signal if $s=\mathrm{f}, m \in\{\varnothing\}$, and if $s=\mathrm{u}, m=s$ ).

(4) Always disclosing a favorable signal, which is true when the signal is indeed favorable $(m=\mathrm{f})$.

(5) Always disclosing an unfavorable signal, which is true when the signal is indeed unfavorable $(m=\mathrm{u})$.

(6) Always misrepresenting - disclosing a favorable signal when it is unfavorable, and disclosing an unfavorable signal when it is favorable $(m \neq s, m \notin\{\varnothing\})$.

(7) $\quad$ Non-disclosure. $(\forall s, m=\varnothing)$. 
The difference between alternative 1 and alternatives 2 and 3 is in the incidence of successful class-action suits. The first three alternatives, however, have the same impact on the market price because they distinguish between good and bad news. If one of these alternatives prevails, the equilibrium coincides with the one analyzed in section 5. Also, note that the sixth alternative reveals the true signal. Therefore, if it is an equilibrium disclosure strategy under $10 \mathrm{~b}-5$, the first alternative of truth-telling can be induced.

\section{OBSERVATION}

a) A contract that induces misrepresentation (alternatives 4 and 5) is inferior to a non- disclosure contract.

b) Any partially revealing contract (alternatives 2 or 3) weakly dominates the fully revealing contract (alternative 1 or 6 ).

Part (a) repeats Observation 2. The proof of part (b) is similar. While the contracting value is the same in a partially-revealing disclosure contract, the latter does not expose the owners to the same level of penalties as under full-revelation disclosure contracts. Q.E.D.

This observation narrows the search for the equilibrium strategy to comparing alternatives 2 or 3 to non-disclosure, depending on which is lower: the expected litigation cost for good news or the expected litigation cost for bad news. When the litigation cost for either good news or bad news exceeds the value of a truth-revealing contract (as per Lemma 1), no firm discloses. If not, the relative expected litigation cost for each signal determines which alternative is more beneficial, either alternative 
2 dominates alternative 3 and hence, Rule 10b-5 suppresses bad-news disclosure, or vice versa. That is, if the expected litigation cost under bad-news disclosure is lower than the expected litigation costs under good-news disclosure, alternative 3 dominates alternative 2. Namely, VMO implement a truth-revealing contract by suppressing good-news disclosure and PMO pool with them by designing a non-disclosure contract. Q.E.D. 


\section{TABLE 1: GLOSSARY}

$s$

$w_{\mathrm{m}} \quad=\quad$ The publicly-observed market demand, $w_{m} \in\left\{\ell_{\mathrm{u}}, \ell \mathrm{f}, \ell \varnothing, h_{\mathrm{u}}, h_{\mathrm{f}}, h \varnothing\right\}$, where $\ell$ stands for low and $h$ for high.

$m$

C

$r$

$\gamma$

$\mathrm{P}^{\mathrm{g}}$

$\mathrm{P}$

$\mathrm{n}$

$\mathrm{p}$

$?_{1 m}$

$\rho_{2 w}$

$?_{n w}$

d

$D^{I}$

$\theta_{a}^{S}$

$\mathrm{W}$

$-\mathrm{V}$

Wo

$w$

$\mathrm{a}^{\mathrm{O}}$

L $\quad=$

$=$ The actual economic outcome, $x \in\left\{x_{1}, x_{2}\right\}, x_{1}<x_{2}$.

$=$ The manager's pre-decision imperfect signal on the state of the world, $s \in\{\mathrm{u}, \mathrm{f}\}$, where $\mathrm{u}$ is unfavorable and $\mathrm{f}$ is favorable.

$=$ The manager's choice of effort, $a \in\left\{a_{\mathrm{p}} a_{\mathrm{g}}\right\}, a_{\mathrm{p}}<a_{\mathrm{g}}$.

$=\quad$ The manager's disclosure (nondisclosure) of his private signal on the state-ofthe-world. $m \in\{\mathrm{u}, \mathrm{f}\} \cup\{\varnothing\}$.

$=$ The contract of the manager, $C(m, \mathrm{P}, r)$.

$=$ The audited reported outcome, $r \in\left\{x_{1}, x_{2}\right\}$.

$=$ The prior probability that the manager's pre-decision signal is favorable, $s=\mathrm{f}$.

$=$ The gross market price.

$=$ The market price, equals to the gross market price less the expected manager's compensation.

$=\quad$ The private signal of the informed traders, $\mathrm{n} \in\left\{x_{1}, x_{2}\right\}$.

$=\quad$ The conditional probability that the audit discovers the manager misrepresented the outcome to him, $1 / 2<\mathrm{p}<1$.

$=\quad$ The conditional probability that $\mathrm{n}$ reflects $x$, i.e., $\operatorname{Prob}\left[\mathrm{n}_{\mathrm{t}} \mid x_{\mathrm{t}}\right], \mathrm{t}=1,2$.

$=$ The conditional probability that high (low) market demand, $w_{m}$ is associated with high (low) demand of informed traders, i.e., Prob $\left[w_{m}=h_{m}^{\mathrm{I}} \mid h_{m}\right]=?_{2 \mathrm{~h}}>1 / 2$. $\operatorname{Prob}\left[w_{m}=\ell_{m}^{\mathrm{I}} \mid 1_{\mathrm{f}}\right]=\rho_{2 \ell}>1 / 2$.

$=$ The conditional probability that high (low) market demand, $w_{m}$ is associated with $x_{2}\left(x_{1}\right), ?_{m w}=?_{1 m} ?_{2 w}+\left(1-?_{1 m}\right)\left(1-?_{2 w}\right)$.

$=$ The proportion of VM firms.

$=$ The informed traders' demand function. The actual demand is either low, $\ell_{m}^{\mathrm{I}}$, or high, $h_{m}^{\mathrm{I}}$.

$=\operatorname{Prob}\left[x=x_{2} \mid s, a\right]$; the probability of $x_{2}$, conditional on the realized pre-decision signal and the manager's effort.

$=\quad$ The utility of the manager over monetary reward.

$=\quad$ The manager's disutility over effort.

$=\quad$ The manager's reservation utility.

$=\quad$ The market demand

$=\quad$ An indicator function, $\mathrm{a}^{\mathrm{O}}=1$ if owners type $\mathrm{O}$ sell on Date $3, \mathrm{a}^{\mathrm{O}}=0$ otherwise.

$=\quad$ The disutility to the market-maker when the Date 3 price deviates from the Date-5 liquidating dividends. 
TABLE 2: THE MARKET PRICE UPON

GOOD-NEWS DISCLOSURE WHEN d IS LOW

\begin{tabular}{|l|l|l|l|}
\hline \multicolumn{2}{|c|}{ T H E M A R K E T - M A K E R } \\
\hline $\begin{array}{l}\text { PMO } \\
\text { design }\end{array}$ & $\begin{array}{l}\text { Truth-inducing } \\
\text { Contract }\end{array}$ & $\begin{array}{l}\text { believes } \\
\left.\text { P(f, } w_{f}\right)=\mathrm{A}\left(w_{f}\right)\end{array}$ & $\begin{array}{l}\text { Does not believe } \\
\mathrm{P}\left(\mathrm{f}, w_{f}\right) \text { as in } \\
\text { equation } 2 .\end{array}$ \\
& Good-news contract & $\mathrm{P}\left(\mathrm{f}, w_{f}\right)=\mathrm{A}\left(w_{f}\right)$ & $\begin{array}{l}\mathrm{P}\left(\mathrm{f}, w_{\mathrm{f}}\right) \text { as in } \\
\text { equation } 2 .\end{array}$ \\
& & & \\
\hline
\end{tabular}

Legend:

- The best response of PMO.

- The best response of the market-maker 


\section{TABLE 3: INCINDECE OF RULE 10B-5 RECOVERIES UNDER DIFFERENT PRICES AND DISCLOSURES ${ }^{31}$}

\begin{tabular}{|c|c|c|c|}
\hline $\begin{array}{l}\text { The firm discloses } \\
(m) *\end{array}$ & $\begin{array}{l}\text { Price } \\
\text { (P) }\end{array}$ & $\begin{array}{l}\text { Report of a high } \\
\text { outcome } \\
\left(r=x_{2}\right)\end{array}$ & $\begin{array}{l}\text { Report of a low } \\
\text { outcome } \\
\left(r=x_{1}\right)\end{array}$ \\
\hline Good news & $\mathrm{P}\left(\mathrm{f}, h_{\mathrm{f}}\right)$ & $0^{1}$ & Purchasers claim $D^{f}$ \\
\hline Good news & $P\left(f, \ell_{f}\right)$ & $0^{1}$ & $0^{2}$ \\
\hline Bad news & $\mathrm{P}\left(\mathrm{u}, h_{\mathrm{u}}\right)$ & $0^{2}$ & $0^{1}$ \\
\hline Bad news & $\mathrm{P}\left(\mathrm{u}, \ell_{\mathrm{u}}\right)$ & Sellers claim $\mathrm{D}^{\mathrm{u}}$ & $0^{1}$ \\
\hline Non-disclosure & $\mathrm{P}\left(\varnothing, h_{\varnothing}\right)$ & $0^{3}$ & $0^{3}$ \\
\hline Non-disclosure & $\mathrm{P}(\varnothing, \ell \varnothing)$ & $0^{3}$ & $0^{3}$ \\
\hline
\end{tabular}

Legend:

1 Rule 10b-5 is not invoked because the reported outcome conforms to the voluntary disclosure.

2 Rule 10b-5 cannot be invoked because the conflicting market demand signal imples that there was "information on the market."

3 Rule 10b-5 cannot be invoked because the information is not subject to an "affirmative duty to disclose."

\footnotetext{
${ }^{31}$ Partial disclosure (i.e., the firm either truthfully discloses only the favorable signal, or truthfully discloses only the unfavorable signal) is not considered.
} 
TABLE 4: STATEGIES AND OBJECTIVE FUNCTIONS

\begin{tabular}{l|l|l|}
\hline \multicolumn{1}{c|}{ Player } & \multicolumn{1}{|c|}{ Strategy } & Objective function \\
\hline $\begin{array}{l}\text { Owner } \\
\text { type } \\
\mathrm{PMO}\end{array}$ & $\begin{array}{l}\text { Date of exit, a } \\
\text { and the manager's } \\
\text { contract, } C^{\mathrm{PMO}} .\end{array}$ & $\begin{array}{l}\text { Maximize expected wealth, } \mathrm{W}_{3}^{\mathrm{PMO}}\left(m, w_{m}\right)= \\
\mathrm{a}^{\mathrm{PMO}} \mathrm{P}\left(m, w_{m}\right)+\left(1-\mathrm{a}^{\mathrm{PMO}}\right) \mathrm{E}\left(x-C^{\mathrm{PMO}} \mid \mathrm{I}^{\mathrm{PMO}}\right] .\end{array}$ \\
\hline $\begin{array}{l}\text { Owner } \\
\text { type } \\
\text { VMO }\end{array}$ & $\begin{array}{l}\text { The manager's } \\
\text { contract, } C\end{array}$ & $\begin{array}{l}\text { Maximize expected liquidating dividends, } \\
\mathrm{E}\left(x-C^{\mathrm{VMO}} \mid \mathrm{I}^{\mathrm{VMO}}\right] .\end{array}$ \\
\hline Manager & $\begin{array}{l}\text { effort, } a, \text { and } \\
\text { disclosure, } m .\end{array}$ & Maximize expected utility, $\mathrm{E}[\mathrm{W}(C(m, \mathrm{P}, r))]-\mathrm{V}(a)$. \\
\hline $\begin{array}{l}\text { Market- } \\
\text { maker }\end{array}$ & $\begin{array}{l}\text { Setting the market } \\
\text { price, } \mathrm{P}\left(m, w_{m}\right) .\end{array}$ & $\begin{array}{l}\text { To break even, } \\
\text { min } \mathrm{L}=-\left|\mathrm{P}\left(m, w_{m}\right)-\mathrm{E}\left(x-C \mid m, w_{m}\right)\right| .\end{array}$ \\
\hline
\end{tabular}

\footnotetext{
${ }^{32}$ We assume that VMO always stay until Date 5.
} 
TABLE 5: THE REDUCED STRATEGIC FORM

WHEN VMO DESIGN A TRUTH-INDUCING CONTRACT*33

\begin{tabular}{|c|c|c|}
\hline $\begin{array}{l}\text { MARKET MAKER } \\
P M O\end{array}$ & Believe disclosure & Believe bad-news only \\
\hline $\begin{array}{l}\text { Truth-inducing contract } \\
\text { and Sell on Date } 3 \\
\text { Truth-inducing contract } \\
\text { and Stay until Date } 5 \\
\text { Good-news contract and } \\
\text { Sell on Date } 3 \\
\text { Good-news contract and } \\
\text { Stay until Date } 5\end{array}$ & $\begin{array}{l}\mathrm{A}, 0, \mathrm{~A} \\
\mathrm{~A}, 0, \mathrm{~A} \\
\mathrm{~A}\left(w_{\mathrm{f}}\right), \mathrm{L}, \mathrm{A} \\
\mathrm{A}, \mathrm{L}, \mathrm{A}\end{array}$ & $\begin{array}{c}\gamma \mathrm{P}\left(\mathrm{f}, w_{\mathrm{f}}\right)+(1-\gamma) \mathrm{P}\left(\mathrm{u}, w_{\mathrm{u}}\right), \mathrm{L}, \mathrm{A} \\
\mathrm{A}, \mathrm{L}, \mathrm{A} \\
\diamond \mathrm{P}\left(\mathrm{f}, w_{\mathrm{f}}\right), 0, \mathrm{~A} \\
\bigcirc \\
\mathrm{A}, 0, \mathrm{~A}\end{array}$ \\
\hline
\end{tabular}

Legend:

$\downarrow=$ The best response of PMO.

= The best response of the market-maker.

$\mathrm{A}=\quad$ The expected liquidating dividends of a firm whose manager reveals the truth, $\mathrm{E}\left[x-C\left(m, w_{n o} r \mid m=s\right]<\mathrm{P}\left(\mathrm{f}, w_{f}\right)\right.$.

$\mathrm{L}=\quad$ The reduction in the utility of the market-maker caused by setting a price that differs from the Date- 5 expected liquidating dividends, $\mathrm{L}=-\left|\mathrm{P}\left(m, w_{m}\right)-\mathrm{E}\left(x-C \mid m, w_{m}\right)\right|$.

${ }^{33}$ PMO are the row player (whose payoff is designated by the first number), the market-maker is the column player (whose payoff is designated by the second number), and VMO are the matrix player (whose payoff is designated by the third number) 
TABLE 6: THE LITIGATION COST OF VMO FOR A GIVEN PROFILE OF DISCLOSURE STRATEGIES WHEN THE MARKET MAKER SETS THE PRICE BY BAYES' RULE WHEEVER POSSIBLE

\begin{tabular}{|c|c|c|c|c|}
\hline . & $\begin{array}{l}\text { PMO design } \\
\text { Truth-telling } \\
\text { disclosure } \\
\text { policy }\end{array}$ & $\begin{array}{l}\text { PMO design } \\
\text { Good-news } \\
\text { disclosure } \\
\text { strategy }\end{array}$ & $\begin{array}{l}\text { PMO design } \\
\text { Bad-news } \\
\text { disclosure } \\
\text { strategy }\end{array}$ & $\begin{array}{l}\text { PMO design } \\
\text { Non- } \\
\text { disclosure } \\
\text { strategy }\end{array}$ \\
\hline $\begin{array}{l}\text { Non- } \\
\text { disclosure } \\
\text { strategy }\end{array}$ & 1) & 1) & 1) & 1) \\
\hline $\begin{array}{l}\text { Good-news } \\
\text { disclosure } \\
\text { strategy }\end{array}$ & $\begin{array}{l}\text { 2) } \\
D \in\left\{0, D^{f}\right\}\end{array}$ & 4) & 5) & 4) \\
\hline $\begin{array}{l}\text { Bad-news } \\
\text { disclosure } \\
\text { strategy }\end{array}$ & 3) $\quad \mathrm{D}^{\mathrm{u}}$ & 3) & 6) $\quad \mathrm{D}^{\mathrm{u}}$ & 6) $\quad \mathrm{D}^{\mathrm{u}}$ \\
\hline
\end{tabular}


FIGURE 1: THE TIMELINE

\begin{tabular}{|c|c|c|c|c|}
\hline Date 1 & Date 2 & Date 3 & Date 4 & Date 5 \\
\hline $\begin{array}{l}\text { Owners } \\
\text { design the } \\
\text { manager's } \\
\text { contracts. }\end{array}$ & $\begin{array}{l}\text { The manager } \\
\text { observes an } \\
\text { imperfect } \\
\text { signal on } \\
\text { the state. } \\
\text { He chooses } \\
\text { unobservable } \\
\text { effort. }\end{array}$ & $\begin{array}{l}\text { The outcome is } \\
\text { realized but not } \\
\text { observed. The } \\
\text { firm may disclose } \\
\text { the signal on the } \\
\text { state. Traders can } \\
\text { buy a signal. The } \\
\text { market-maker sets } \\
\text { the price. The } \\
\text { owners may sell } \\
\text { their shares. }\end{array}$ & $\begin{array}{l}\text { The manager } \\
\text { observes the } \\
\text { outcome and } \\
\text { communicates it } \\
\text { to the auditor. } \\
\text { The firm } \\
\text { publicizes the } \\
\text { audited report. } \\
\text { The manager is } \\
\text { paid. }\end{array}$ & $\begin{array}{l}\text { The firm } \\
\text { liquidates. } \\
\text { The owners } \\
\text { collect net } \\
\text { liquidating } \\
\text { dividends. }\end{array}$ \\
\hline
\end{tabular}


FIGURE 2: The Market Subgame's Equilibrium Path

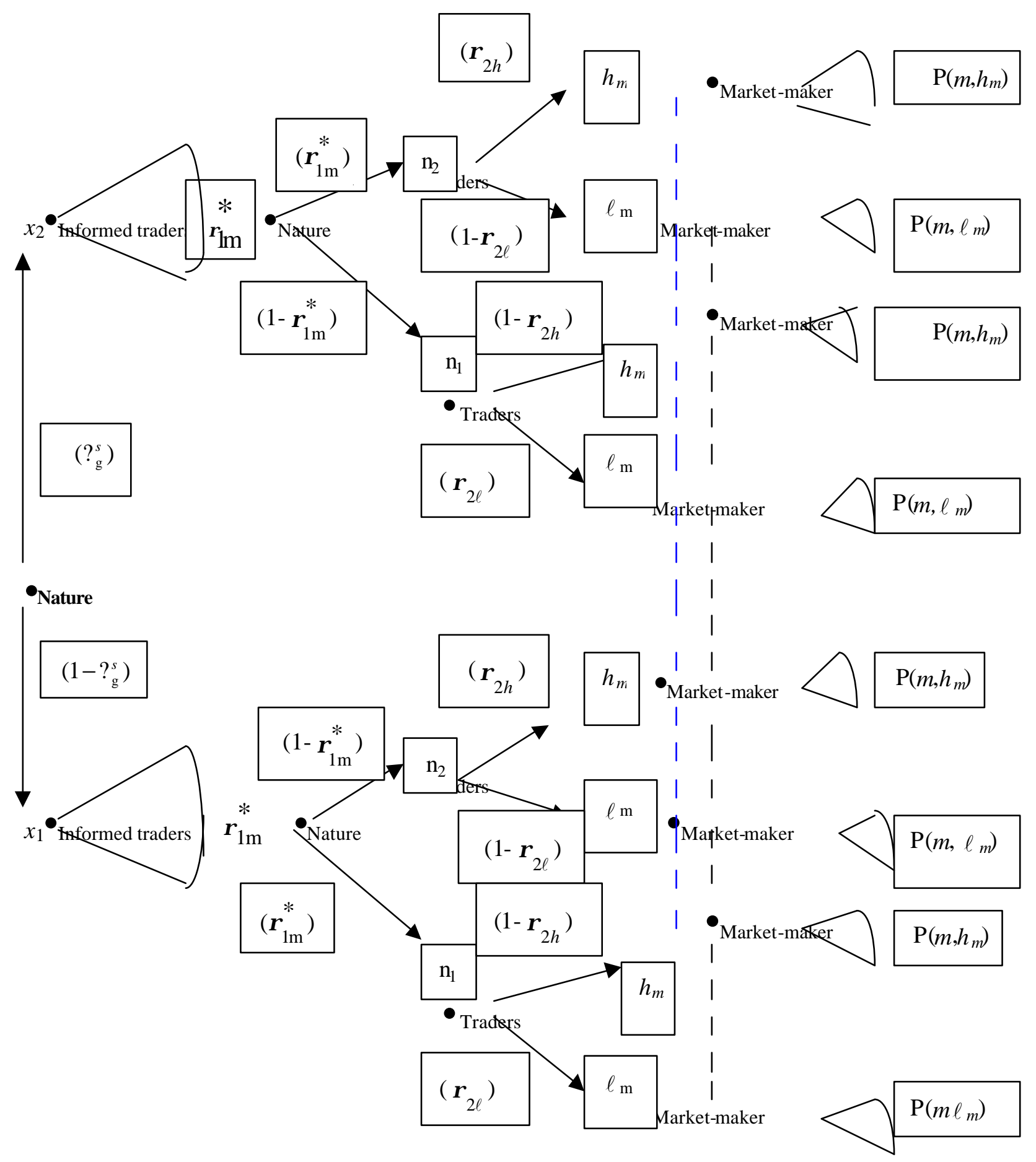


FIGURE 3: HIGHLIGHTS OF THE

EXTENSIVE FROM OF THE GAME

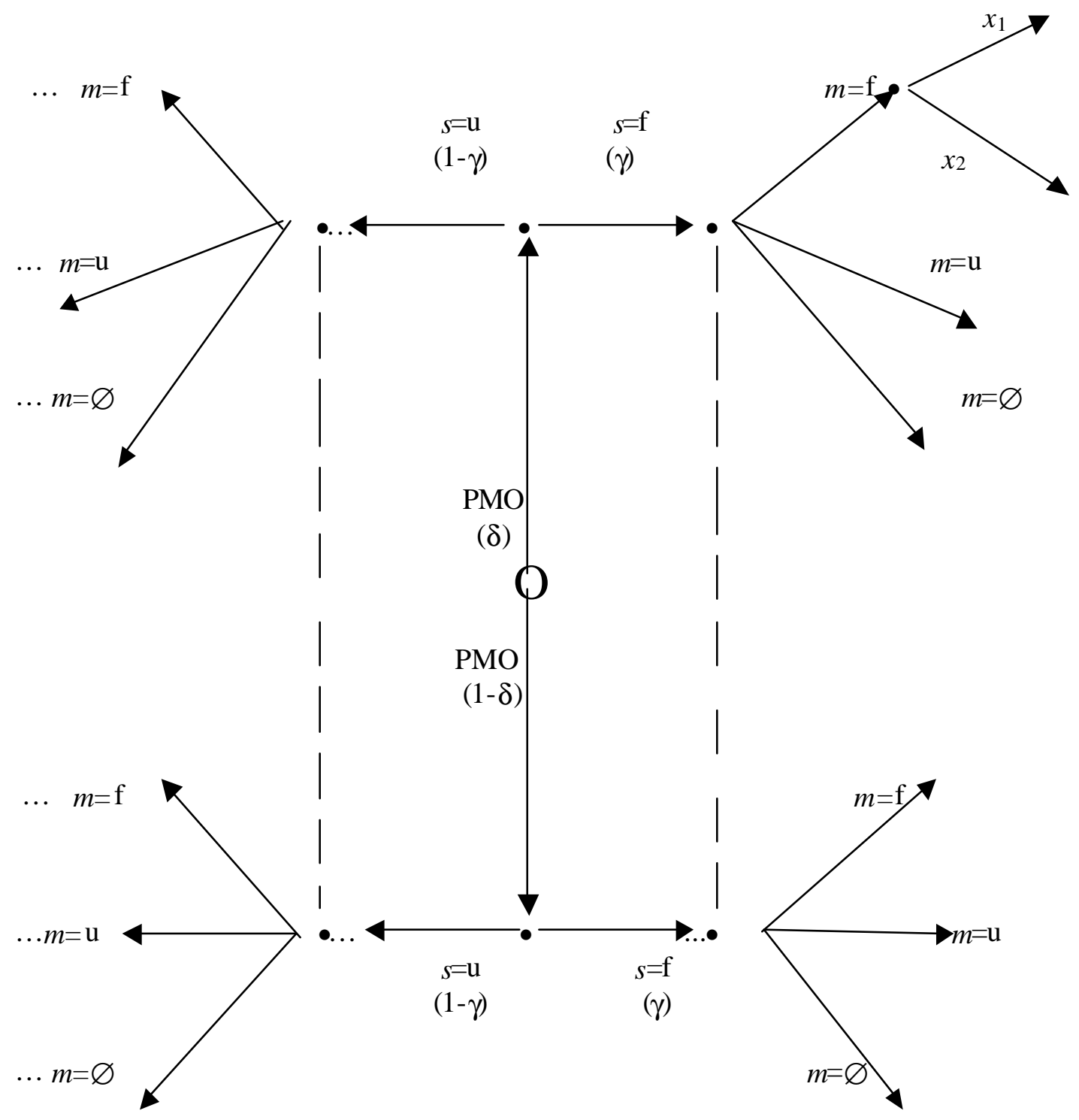

